Review

\title{
From 2-D to 0-D Boron Nitride Materials, The Next Challenge
}

\author{
Luigi Stagi $₫$, Junkai Ren $₫$ and Plinio Innocenzi * \\ Laboratorio di Scienza dei Materiali e Nanotecnologie, CR-INSTM, Dipartimento di Chimica e Farmacia, \\ Università di Sassari, Via Vienna 2, 07100 Sassari, Italy; lstagi@uniss.it (L.S.); j.ren@studenti.uniss.it (J.R.) \\ * Correspondence: plinio@uniss.it
}

Received: 8 October 2019; Accepted: 22 November 2019; Published: 26 November 2019

\begin{abstract}
The discovery of graphene has paved the way for intense research into 2D materials which is expected to have a tremendous impact on our knowledge of material properties in small dimensions. Among other materials, boron nitride (BN) nanomaterials have shown remarkable features with the possibility of being used in a large variety of devices. Photonics, aerospace, and medicine are just some of the possible fields where BN has been successfully employed. Poor scalability represents, however, a primary limit of boron nitride. Techniques to limit the number of defects, obtaining large area sheets and the production of significant amounts of homogenous 2D materials are still at an early stage. In most cases, the synthesis process governs defect formation. It is of utmost importance, therefore, to achieve a deep understanding of the mechanism behind the creation of these defects. We reviewed some of the most recent studies on 2D and 0D boron nitride materials. Starting with the theoretical works which describe the correlations between structure and defects, we critically described the main $\mathrm{BN}$ synthesis routes and the properties of the final materials. The main results are summarized to present a general outlook on the current state of the art in this field.
\end{abstract}

Keywords: boron nitride; 2D materials; quantum dots; fluorescence; nanocomposites

\section{Introduction}

Boron nitride $(\mathrm{BN})$ is a chemically stable material exhibiting four different polymorphs: hexagonal (h-BN), cubic (c-BN), rhombohedral ( $r-B N)$, and wurtzite (w-BN) [1-5]. The different BN allotropes have attracted considerable interest as a possible alternative to diamond for their great hardness and high thermal stability [3-6]. Despite a thermal stability higher than diamond (1473 K) and a low reactivity with steel, c-BN still presents a more moderate hardness in comparison with diamond $\left(\mathrm{H}_{\mathrm{V}}=40-60 \mathrm{GPa}\right)$ [3]. Nevertheless, $\mathrm{C}_{2}$-BN nanocomposites (c-BN: diamond, 1:2) can reach a very high hardness, $\mathrm{H}_{\mathrm{V}}=85 \mathrm{GPa}$. More recently, w-BN displayed interesting hardness properties, comparable with the other allotropes [5]. Pure w-BN, treated at a pressure of 10-20 GPa and high temperature $\left(400-1900{ }^{\circ} \mathrm{C}\right.$ ) reached a hardness as high as $\mathrm{H}_{\mathrm{V}}=46 \mathrm{GPa}$. A two-stage shear mechanism is responsible for the unusual hardness of $\mathrm{w}$-BN [6].

h-BN presents an $\mathrm{sp}^{2}$ hybridization of B-N bonds, and it crystallizes in a layered structure like graphene (Figure 1). While $\mathrm{B}$ and $\mathrm{N}$ atoms are held together with strong covalent bonds densely covering the plane, the different BN layers interact via Van der Waals forces. Contrary to graphene, $\mathrm{B}-\mathrm{N}$ is strongly polarized with electronegative $\mathrm{N}$ and almost vacant $\mathrm{B}$. BN nanoplates are known to preserve their thermal stability up to $1000^{\circ} \mathrm{C}$, undergoing oxidation in the range between 1000-1200 ${ }^{\circ} \mathrm{C}$, with the formation of $\mathrm{B}_{2} \mathrm{O}_{3}$. For thin $\mathrm{BN}$ nanosheets the oxidation process starts at $850{ }^{\circ} \mathrm{C}$ [7-10]. h-BN monolayers present a thermal conductivity of $751 \mathrm{~W} \mathrm{mK}^{-1}$ at $25^{\circ} \mathrm{C}$ conjugating high thermal conductivity with electrical insulation as a good candidate for heat dissipation in future electronic devices [11]. 


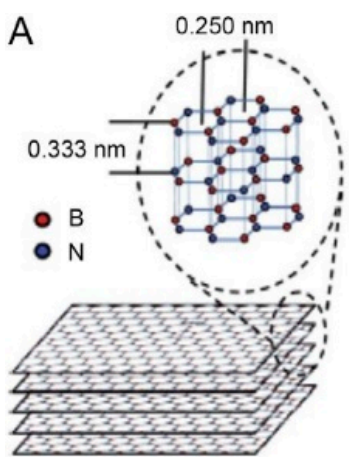

Few-layer h-BN

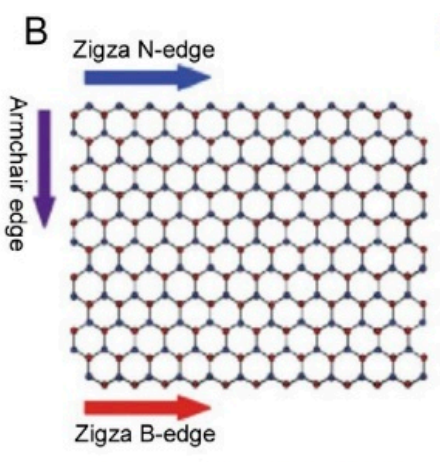

Monolayer h-BN or BNNS

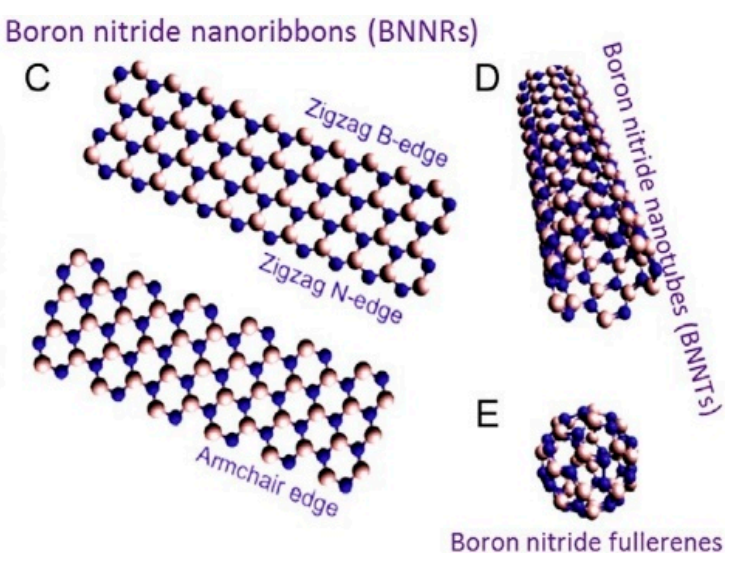

Figure 1. (A) hexagonal boron nitride structures. Layer distance and crystal parameter. (B,C) Different edge terminations. (D,E) different boron nitride shapes: BN nanotubes and BN fullerene. Copyright 2012 and 2014, with permission of refs, $[7,8]$.

Optical spectroscopy measurements on h-BN crystals have demonstrated evidence for an indirect band gap of $5.955 \mathrm{eV}$ [12]. More recently, first principle calculations described the evolution of band gap as a function of the numbers of layers, predicting the crossover to direct band gap at a limit of one layer [13], later verified experimentally by Elias et al. [14].

Boron and nitrogen show the ability to create ordered superstructures under ultra-high vacuum conditions. Borazine, widely used in film depositions, has the tendency to decompose on $\mathrm{Ru}$ and $\mathrm{Rh}$ substrates, forming a self-assembled regular mesh [15-17]. The derived structure presents hexagonal pores at distances of $3.2 \mathrm{~nm}$ and $2 \mathrm{~nm}$ and is produced upon BN adhesion on the metal surface. Correspondingly, $13 \mathrm{~B}$ or $\mathrm{N}$ atoms are located on $12 \mathrm{Rh}$ atoms, which in turn determines the corrugation of the BN system. The periodic repetition of peaks and valleys originates in a uniform BN single layer with potential applications in spintronics, quantum computing, and photochemistry. It has been demonstrated that the nanomeshes could work as templates for molecules and metal nanoparticles. The molecules tend to be trapped into the pores preserving their structures and properties; this opens up new opportunities for molecular electronics [18].

$\mathrm{h}$-BN represents a candidate for p-type layers in nitride deep-ultraviolet (DUV) emitters. Even though the lattice mismatch of h-BN with respect to the c-plane of AlN is more than 19\%, five lattice constants of $\mathrm{BN}$ align with four lattice constants of $\mathrm{AlN}$, reducing the mismatching down to $0.58 \%$ and making feasible a $\mathrm{h}-\mathrm{BN} / \mathrm{w}-\mathrm{AlN}$ heterojunction. Moreover, $\mathrm{h}-\mathrm{BN}$ is a good e-blocking and p-contact layer with w-AlN, showing a type II alignment [19].

Because of their negative electron affinity, BN nanotubes display interesting electron emission properties. Despite the higher turn-on field compared to carbon nanotubes (CNT), BN nanotubes have better thermal stability and can work at high temperature in an oxygen environment [20].

The great versatility of $\mathrm{BN}$ materials enables their application as neutron detectors [21] because of the large cross section of ${ }^{10} \mathrm{~B}$ for thermal neutrons. Maity et al. developed a h-BN detector, composed of two bilayers Ni/Au as ohmic contacts. They exhibited an efficiency of $58 \%$ when exposed to a calibrated neutron source [22].

A porous amorphous $\mathrm{BN}$ has been recently proposed as photocatalyst for the reduction of $\mathrm{CO}_{2}$. It works in the UV region without employing any cocatalyst [23]. Continuous endeavors to extend the $\mathrm{BN}$ application to the visible range have been made to trigger the reactions under solar exposition [24]. Several semiconductors in hybrid systems with $\mathrm{BN}$ were proposed such as $\mathrm{TiO}_{2}, \gamma-\mathrm{C}_{3} \mathrm{~N}_{4}, \mathrm{ZnO}, \mathrm{In}_{2} \mathrm{~S}_{3}$ and many others [24]. In the composites, BN plays a crucial role, promoting the reduction of band gap, through structural strain and inhibiting electron hole recombination [25].

Since the sixties, BN has attracted considerable attention in aerospace applications [26]. Most recently, BN materials have been the focus of a renewed interest in the form of BN nanotubes (BNNTs), 
whose mechanical and thermal properties can be exploited for producing radiation shields, mainly as a reinforcing component [27].

Today's BN research activity can be divided into two main areas. The first regards the improvement of mechanical and thermal properties. The obtained results are somewhat encouraging and involve both the main crystalline phases, h-BN and c-BN. The second focuses on the creation of nanosheets, controlling the number of layers and their structure with a particular interest in 0 - dimensional systems (dots). BN-dots, in particular, have potential applications in several fields such as lighting, catalysis, and bioimaging.

In this brief review, we have considered the most significant results in the synthesis and processing of h-BN systems. We have analyzed the connection between dimensions, shape, and the growth process together with some of the accomplishments of theoretical calculations to identify the most probable defects in the hexagonal structure.

\section{Understanding BN Materials by Theoretical Calculations}

Despite the potential applications in several technological fields, 2D materials are still at their early stage. One of the main challenges is the possibility of interfacing two different layered materials to create new devices. This system would combine the electronic and optical functionalities from every single 2D material [28]. Computational investigations of electronic and optical boron nitride- based materials can provide a more in-depth theoretical insight, paving the way to a more efficient fabrication of devices. The possibility of nanoscale functionalization of the BN crystal structures is the basis of the great attractiveness of this material. In particular, quantum dots exhibit new interesting properties, directly linked to the size of the systems, passivation of their edges, shapes, and atomic or molecular doping [29].

The electronic structure that determines, in turn, the material property, can be computed by density functional theory (DFT)-based models. DFT can calculate and explore magnetic and optical properties, the system geometry and stability, as well as charge transport and structural transformation. Thanks to the increase of computational power, the systems that can be addressed can count thousands of atoms [28]. Although the accessibility to the DFT computing systems is growing, thanks to the increasing availability of user-friendly computing codes such as Quantum Espresso, Gaussian, Siesta, ABINIT, and VASP, the limitations and the efficiency of calculations are still under debate. Reliable correspondence of the calculations with experimental measures represents the main problem for providing a suitable complement to the experimental field [28]. The accuracy of the band gap calculation and the excited states investigation represent two of the main challenges for DFT applications. Standard DFT underestimates the band gap energy and needs to be corrected with the Green's function quasiparticle (GW) method. This computing method has a quasi- particle approach scaling with $\mathrm{N}^{4}$ and, therefore, becomes very expensive for large systems. HSE06 is another choice frequently employed for van der Waals heterostructures. For the calculation of the excited states, time-dependent DFT is the most used, and its results are rather reliable [28].

Berseneva et al. [30] carried out a calculation of the h-BN electronic structure and studied the effect of carbon incorporation on the system properties. GW approximation showed that the band gap of 2D $\mathrm{BN}$ depended on the interlayer distance in the simulation supercell and it differed from bulk band gap by more than $0.5 \mathrm{eV}$ [30]. Band gap values have been calculated using Perdew, Burke, and Ernzerhof (PBE) and Heyd-Scuseria-Ernzerhof functionals (HSE) approaches and GW approximation (with PBE data as input). They reported an indirect band gap of 4.56 and 5.56 for PBE and HSE, respectively. GW calculation seems to fail in the estimation of h-BN sheet, providing a succession of different energy band gap values for a wide range of interlayer distances (up to infinite separation) with no effective converged value [30]. The effect of carbon impurities has been tested in four different configurations by inserting a single $\mathrm{C}$-atom in $\mathrm{N}$ or $\mathrm{B}$ sites and a triangular-shaped carbon unit. What has emerged from the defect formation energies is that a $C$ atom tends to occupy the position of $B$ atoms both in $\mathrm{N}$-rich and B-rich environments. New states, close to the conduction(valence) band appear in the band 
gap with the substitution of $\mathrm{B}(\mathrm{N})$ atoms [30]. When a $\mathrm{B}(\mathrm{N})$ atom is substituted by a carbon atom, an electron (hole) is introduced into the structure, along with the formation of defect levels within the HOMO-LUMO gap of BN quantum dots (BNQDs) [31]. The substitution of $\mathrm{B}(\mathrm{N})$ by $\mathrm{C}$-atom moves the Fermi level to a high(low) energy and the levels near the Fermi level are contributed by a $C 2 p_{z}$ orbital, as shown by the electron density of the state (PDOS) [31]. Moreover, Zhao at al. [31] found that in BNQDs, the $\mathrm{C}$-atom tends to reside in the inner region of the minority sublattice. For the 2C-doped structure, instead, the C-atoms are preferentially located in the edge positions [31]. DFT calculations on $\mathrm{B}_{11} \mathrm{C}_{12} \mathrm{~N}_{9}$ (doping with aromatic carbon) compounds have shown a remarkable reduction of band gap down to $2 \mathrm{eV}$, unveiling potential photocatalytic applications in the visible range [32]. Interestingly, Gao et al. [33] showed that $\mathrm{C}$ doping in the $\mathrm{B}$ position turns the $\mathrm{BN}$ sheets into a catalyzer for $\mathrm{O}_{2}$ activation. This effect is due to the electron transfer from carbon impurity to the $2 \pi^{*}$ antibonding orbital of $\mathrm{O}_{2}$.

Spin-polarized calculations within GGA (generalized gradient approximantion) on electron-acceptor tetracyanoquinodimethane (TCNQ) and electron-donor tertrathiafulvalene (TTF) physisorbed on BNQDs have shown a low dopant-QD interaction due to the absence of a $\pi$-surface [29].

The lower the dimension of the system, the more the edge effects become relevant for structural stability and electronic and magnetic properties. Krepel at al. [34] demonstrated that the hydroxylation of zig-zag edges of $\mathrm{BN}$ is much stronger for nitrogen-rich edges and can produce considerable stabilization of the whole system. This is the most favorable scenario for particles growth in hydrothermal conditions or exposed to water vapor atmosphere. The results were obtained within the B3LYP hybrid exchange-correlation density functional approximation and show that hydroxylation reduces the band gap by more than $30 \%$. This finding points out the importance of edge chemistry on the electronic properties of $\mathrm{BN}$ nanomaterials [34].

BNQDs could display innovative and interesting properties when functionalized with chemical ligands, especially for biomedical and optoelectronic applications [35] Hybrid DFT and Green's function calculations have been carried out on h-BNQDs functionalized by $-\mathrm{H},-\mathrm{OH},-\mathrm{SH},-\mathrm{NH}_{2}$ and $-\mathrm{N}$. As a general trend, the functional groups contribute to reducing the energy band gap. Moreover, the presence of side defects, working as single quantum emitters, could promote the lowest excitation energy in the visible and near infrared regions [35].

Defects engineering in BN nanomaterials is expected to open new frontiers in quantum technologies, such as quantum computing, communications, and metrology [36,37]. Single-photon emission from 2D BN was experimentally demonstrated by Tran et al. [36]. The bright emission, recorded at $623 \mathrm{~nm}$ at room temperature, was attributed to radiative recombination by structural defects. Attaccalite et al. [38] predicted a UV emission associated with boron vacancies $\left(V_{B}\right)$. DFT calculations with PBE exchange-correlation functional showed that the most likely candidate for the quantum emitter is $\mathrm{N}_{\mathrm{B}} \mathrm{V}_{\mathrm{N}}$, i.e. an anti-site nitrogen-vacancy (nitrogen occupies a boron site, and there is a vacancy at the nitrogen site) [36]. In the framework of quantum computing, group analysis along with DFT calculations demonstrated that the neutral paramagnetic carbon defect $C_{B} V_{N}$ could be a valid candidate for spin coherent manipulation and qubit, as well as $C_{N} V_{B}$ [39-41]. Recently, Weston et al. attributed the single-photon emission in the UV and at about $2 \mathrm{eV}$ to carbon substituting nitrogen and interstitial centers, respectively [42]. According to the formation energy, it is more likely to be the incorporation of an oxygen atom in an $\mathrm{N}$ site rather than in a $\mathrm{B}$ site. $\mathrm{O}_{\mathrm{N}}$ defect has been reported to lie at $5.3 \mathrm{eV}$, above the valence band, and it acts as a donor. $\mathrm{V}_{\mathrm{B}} \mathrm{O}_{\mathrm{N}}$ could introduce more levels inside the gap at lower energies, but it has high formation energy. Oxygen can be present in the form of interstitial defects $\left(\mathrm{O}_{\mathrm{i}}\right)$ at $2.93 \mathrm{eV}$ above the valence band. Furthermore, thanks to their high mobility, even at room temperature, $\mathrm{O}_{\mathrm{i}}$ can form complexes in place of isolated defects [42]. 


\section{Making of 2D BN Materials}

According to the available fabrication methods, we can distinguish the preparations of nanomaterials by two different approaches, namely the two typical top-down and bottom-up routes. Their applicability relies on the dimensions, purity, costs, and time necessary to obtain the final products.

The 2-D materials represent a peculiar case, where the possibility to unleash the outstanding properties deriving from their layered structures, represents the primary goal of every growth approach. The choice of specific synthesis and processes depends on several key factors such as yield, ease of implementation, production pace, defects generation, precursors, and potential scalability [43,44]. The production of monolayers or a few layers of $\mathrm{h}-\mathrm{BN}$ is the main target of the two methods. With a very rough simplification, the top-down approach is based on the exfoliation of the stacked structure of raw BN materials (mainly in the form of powder). The exfoliation, in general, produces BN sheets of a few layers. The chemical reactions of molecular precursors are at the base of the bottom-up approach $[45,46]$. Liquid phase methods are also employed for the fabrication of nanosystems. Thanks to the reduced processing cost, they are promising routes for large scale production. Regarding the case of BN, hydro/solvothermal methods are suitable for the preparation of dots, small clusters, and flakes [47-49]. Besides, it is not unusual to carry out a combination of top-down and liquid phase synthesis with the purpose of enhancing the reduction of bulk BN in sheets and functionalizing them [50-52].

\subsection{Top-Down Synthesis Routes}

When top-down synthesis is employed, a large piece of material (bulk) transforms into a fine powder by applying a certain amount of external energy until the system is scaled down to nanosize. Among others, mechanosynthesis is a low-cost and reliable method for nanomaterials production [46]. The main result of the mechanical approach is the exfoliation into layers of various sizes, which can be made smaller by further processing cycles.

Since its application to graphene [53], the "scotch-tape" method has been considered easy and reliable for obtaining a small amount of 2D materials. The weak Van der Waals forces can be overcome by subsequently tear movements until the monolayer is reached [54]. As shown by Tang et al, the peeling-off process bends and extracts the layer preserving its high crystallinity and related electronic properties [55]. Despite the advantage of high-quality samples, BN cleavage in sheets by the scotch method does not enable large scale uses but only laboratory applications [10].

Another top-down method is ball-milling. A ball-milling system provides the kinetic energy for reducing the material into small fragments. Besides, the involved energy may start chemical reactions, paving the way for fast organic synthesis [56]. Many parameters control the ball-milling processes $[57,58]$ such as ball-to-power ratio, processing time, milling speed, and ball size. The choice of the parameters depends on the desired dimensions and, in the case of BN materials, also affects the exfoliation process. Sheets of BN have been produced by applying shear forces to break the interplanar bonds. A milling speed of $800 \mathrm{rpm}$ with a ball-to-powder weight ratio of 10:1 is capable of producing exfoliated BN sheets efficiently. With $10 \mathrm{~h}$ of treatment, $0.1-0.2 \mathrm{~mm}$ balls could provide crystalline BN sheets with low damaged structures. The ball-milled products were then tested with oil and showed an improvement in lubricating properties [57] (Figure 2). 

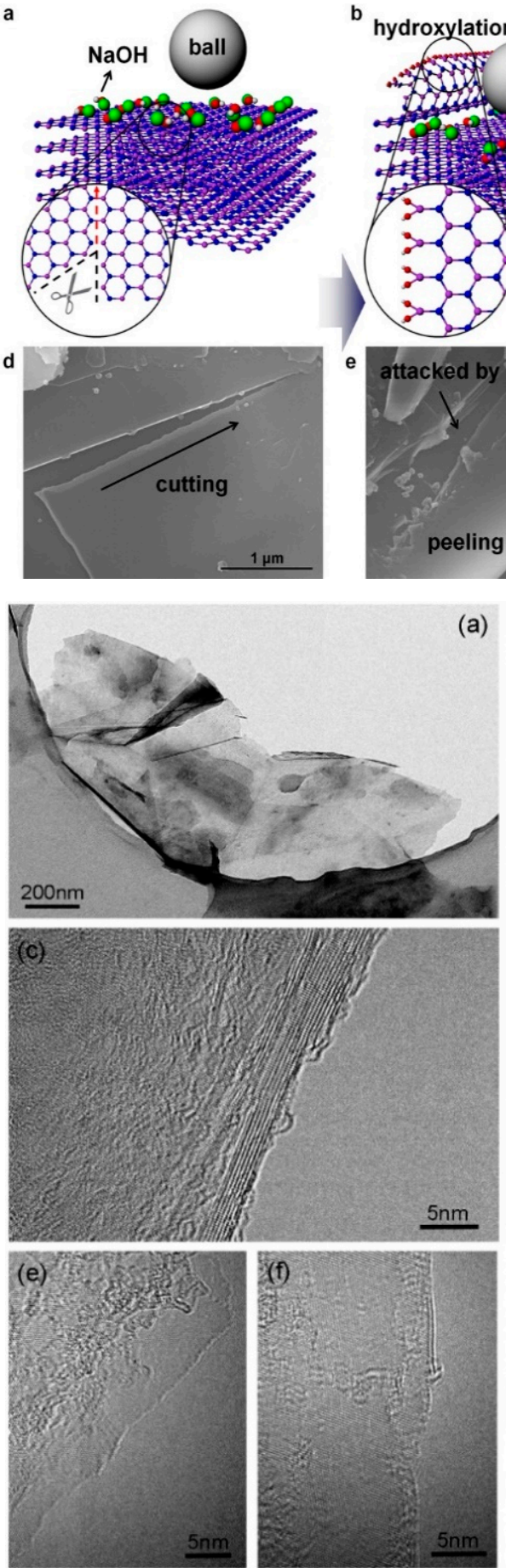

(a)

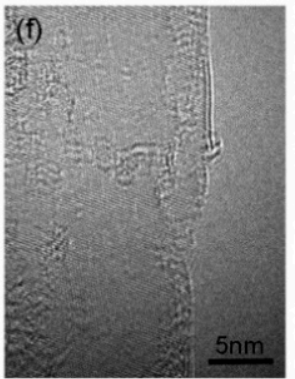

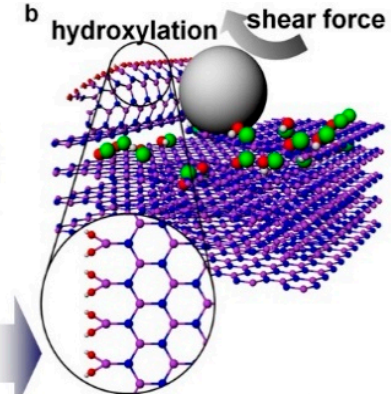
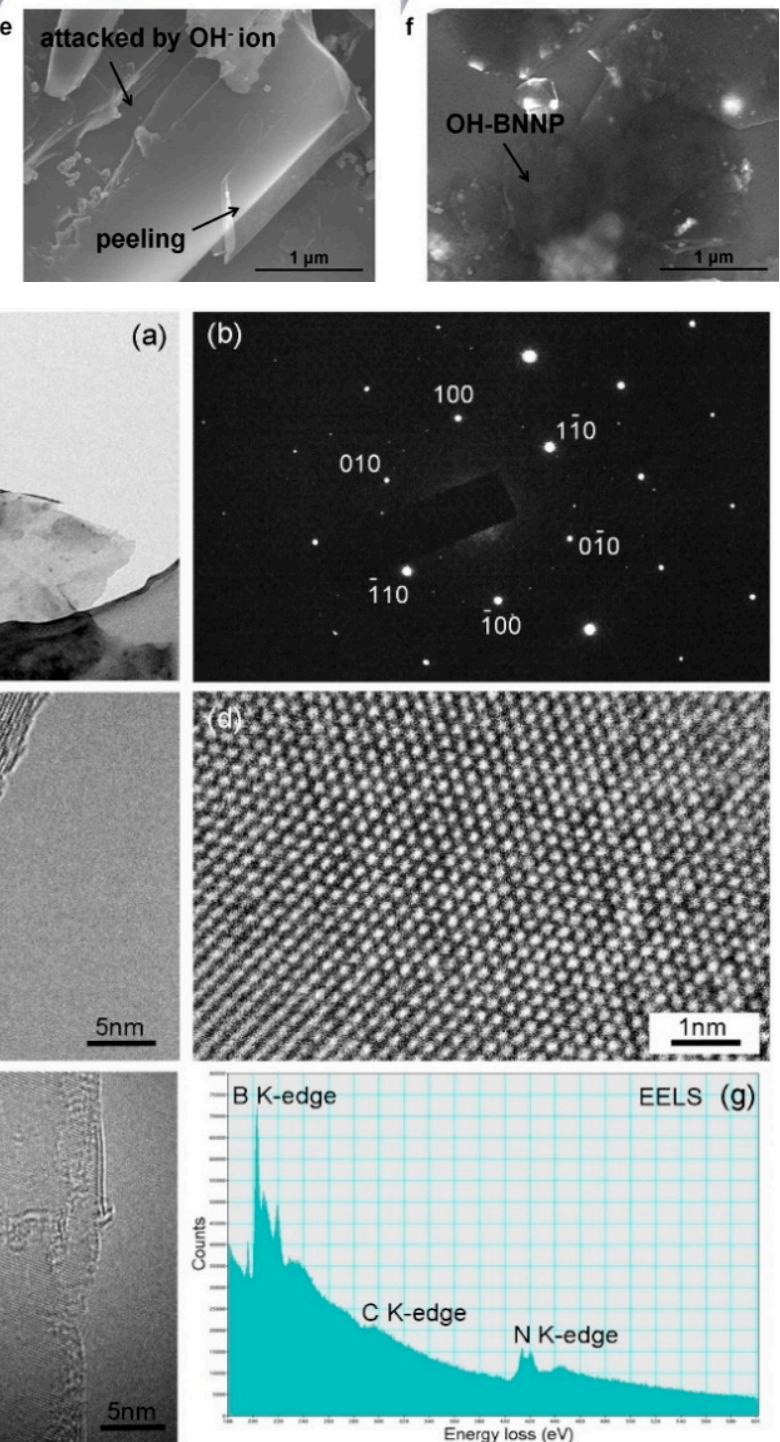

Figure 2. On top: Schematic diagram of exfoliation mechanism. Copyright 2015, with permission of [58]. On bottom: (a) TEM Images of the BN sheets produced by $0.1-0.2 \mathrm{~mm}$ balls; (b) the corresponding SAED pattern; (c,d) high-magnification TEM images; (e,f) TEM images of few-layer BN nanosheets (g) EELS spectra of the BN nanosheet. Copyright 2014, with permission of [57].

The peeling mechanism for BN sheets is solvent dependent. Li et al. [59] demonstrated the effectiveness of benzyl benzoate over other milling agents like water, ethanol or dodecane. The benzyl benzoate enhances the exfoliation process due to its higher viscosity and hinders the formation of sheets agglomerates. Besides, due to the low reactivity of benzyl benzoate with Fe and the higher viscosity, which reduces the ball impact, the authors measured less steel contamination (from the vials and balls) in comparison to other milling agents [59]. 
High-pressure microfluidization has been used for cleavage BN micropowders into thin fragments with encouraging results [60]. A solution of $\mathrm{BN}$ precursors in $\mathrm{DMF} /$ chloroform was accelerated by a pump up to $400 \mathrm{~m} \mathrm{~s}^{-1}$, with a pressure of 2069 bar, before being introduced into an interaction chamber made of multiple microchannels. The BN precursors were forced to collide at high energy, breaking into small pieces, approximately of few microns in-plane and $12 \mathrm{~nm}$ in thickness, corresponding to 20-30 BN monolayers (Figure 3) [60].

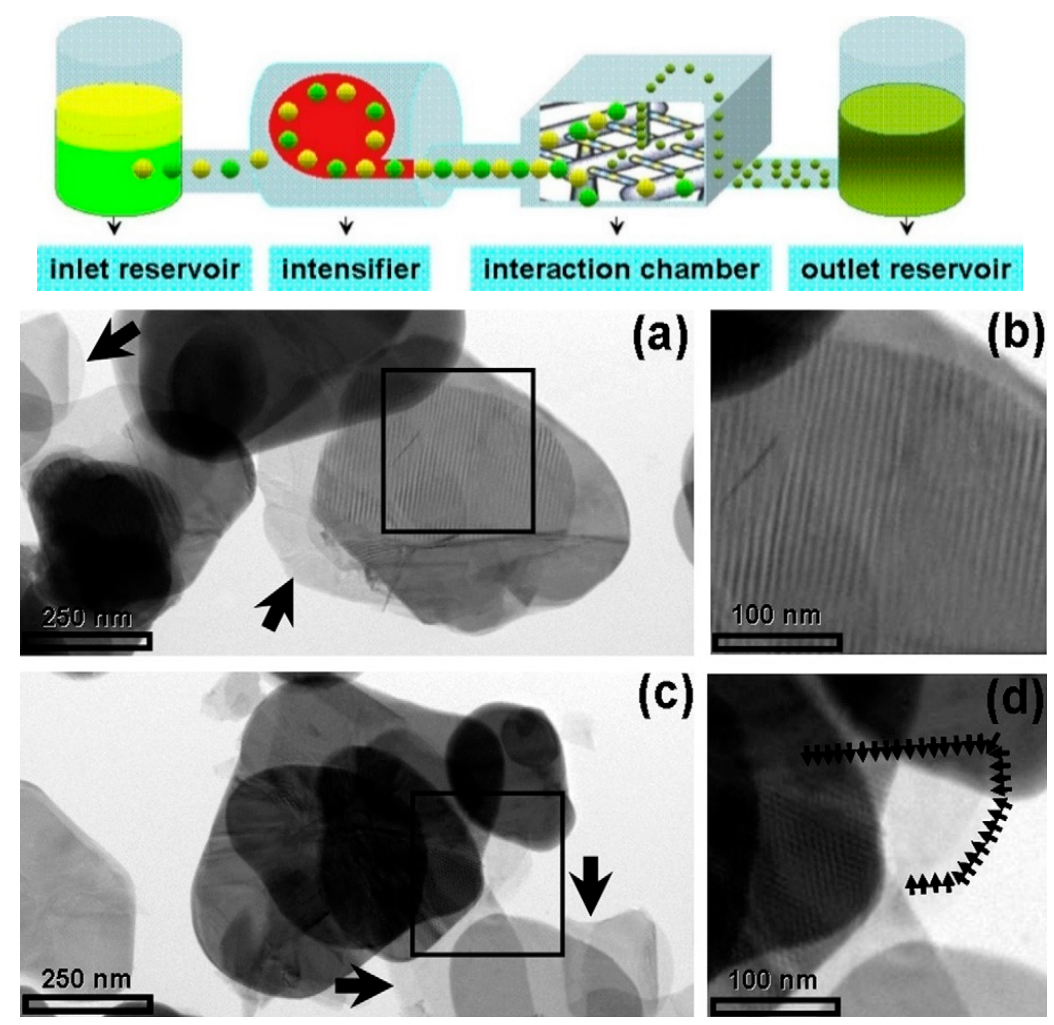

Figure 3. On the top: Schematic representation of a microfluidizer processor. Below: Low magnification TEM images: transparent regions indicated by arrows refer to a few layers of boron nitride nanosheets. Copyright 2012, with permission of [60].

A less sophisticated apparatus based on a rotating glass inclined at $45^{\circ}$, was used to combine centrifugal and gravitational forces to enhance the exfoliation of graphene and $\mathrm{BN}$ in N-Methyl-2-pyrrolidone (NMP). BN sheets with an average flake dimension of 2-3 $\mu$ m were obtained using an optimal speed of $8000 \mathrm{rpm}$ [61].

Despite the method being simple and the quality of the nanosheets being good [59], ball milling and vortex fluidic methods turn out to be still inefficient for the preparation of 2D BN in high yields. This low efficiency hampers its applicability for large scale manufacturing [62].

The exfoliation process with the highest yield is chemical assisted exfoliation [62,63]. With the aid of a sonication bath, the layered BN structure can be reduced in foil and dispersed in a solvent. The efficacy of the process depends on the type of solvent, energy, and time $[64,65]$. The sonication treatment generates a succession of compression and rarefaction. The cavitation microbubbles tend to grow at each cycle, collapse, and generate shockwaves $[65,66]$.

$\mathrm{BN}$ exfoliation was reported for the first time by Han et al. An amount of $0.2 \mathrm{mg}$ of BN single crystals was added to $5 \mathrm{~mL}$ of a 1,2-dichloroethane solution of poly(m-phenylenevinylene) -co-2,5-dioctoxy-p-phenylenevinylene for $1 \mathrm{~h}$. The sonication process was able to break up the BN bulk into mono- and a few layers. The time treatment represents a compromise between sonication efficacy and damage of the structure [67]. 
The correct choice of the solvent is important to consider for the surface energy of the nanosheets. The most efficient solvent is one with a similar surface energy. This worked very well with isopropyl alcohol (IPA) and N-methyl-2-pyrrolidone (NMP) for BN, which possesses a surface energy of $65 \mathrm{~mJ} \mathrm{~m}^{-2}[45,68,69]$. Since then, many other solvents have been tested such as dimethylformamide (DMF) [70], ammonium hydrogen carbonate [71], methanol [72], sulfuric acid [73] or ammonia [74].

Water represents a particular case of BN exfoliation. Li et al. have demonstrated the high effectiveness of water in the production of nanosheets. However, BN tended to react with water forming ammonia and underwent edge functionalization with $\mathrm{OH}$ groups [75].

$\mathrm{BN}$ edges can be affected by protonation in the presence of acid. The presence of repulsive charges can favor the separation of layers, as in the case of graphite [76]. The typical yield of dispersed BN nanosheets, in a mixture of $\mathrm{H}_{3} \mathrm{PO}_{4}$ and $\mathrm{H}_{2} \mathrm{SO}_{4}$ (ratio 1:8), is between $12 \%$ and $15 \%$ of the precursors [76], comparable with methanesulfonic acid $\left(\mathrm{CH}_{3} \mathrm{SO}_{3} \mathrm{H}\right)$ [77].

In summary, the progressive reduction of the bulk material down to nanometric sizes is the basis of the main top-down methods. For a 2D material, this implies progressive exfoliation of the system into one or a few layers. We have seen how, to date, top-down processes suffer from poor material yield, but have the advantage of affecting the crystalline structure very little, except at its edges, where functionalizing molecular groups can be easily present. For example, in an $\mathrm{OH}$-rich environment, the presence of such groups in $\mathrm{BN}$ nanostructures is common.

\subsection{Bottom-Up Synthesis Routes}

In the bottom-up approach, the final composite material is prepared by starting from the elemental or molecular components and allowing them to react and assemble into the required structure.

One of the main techniques which guarantees a high purity and low defect layered material is the chemical vapor deposition (CVD) method. The first work on hexagonal BN was reported by Paffett et al. [78]. They described the procedure for a single layer deposition of $\mathrm{BN}$ on $\mathrm{Pt}(111)$ and $\mathrm{Ru}(001)$ substrates. The data collected on adsorption and decomposition of borazine $\left(\mathrm{B}_{3} \mathrm{~N}_{4} \mathrm{H}_{6}\right)$, revealed a better reactivity for Pt substrate with a coverage ratio of 0.36 against 0.15 for $\mathrm{Ru}$. Later, Nagashima et al. [79] successfully deposited a layer of h-BN on a substrate of $\mathrm{Ni}(111)$ heated at $800^{\circ} \mathrm{C}$.

Both of the experiments mentioned above used borazine as the precursor. Since borazine is toxic and liquid at room temperature, considerable efforts have been made to find alternative precursors for h-BN by CVD. Among others, B-trichloroborazine $(\mathrm{ClBNH})_{3}$ shows stability and easy handling [80].

The CVD method is affected, in general, by the precursor chemistry and substrate. Corso et al. unveiled the impact of the substrate on h-BN morphology, showing how the nanomesh of BN resulted on $\mathrm{Ru}$ (0001) and $\mathrm{Rh}$ (001), while a flat layer was obtained on Pd (111), $\mathrm{Pt}$ (111), $\mathrm{Cu}$ (111), Mo (110), $\mathrm{Cr}$ (110), $\mathrm{Fe}$ (110), and $\mathrm{Ni}$ (111) [15]. If polycrystalline substrates of $\mathrm{Ni}$ or $\mathrm{Cu}$ are employed, the CVD method can also provide high purity BN nanosheets with decaborane/ammonia as precursors [81]. Although CVD has the advantage of being able to grow single BN sheets of high quality on a large variety of substrates, with high control of possible foreign elements, this technique is unfortunately still far from being used for large regions of the substrate and for high control over multiple layers. In this respect, Jeong et al. displayed encouraging results (Figure 4). They grew large scale h-BN on $\mathrm{Ni}$ (111) substrate; the ammonia, used as a precursor, tended to be adsorbed and decomposed on $\mathrm{Ni}$. The decomposition produces radicals and forms an extended portion of high-crystalline h-BN. This effect turned out to be hardly reproducible on sapphire, demonstrating the importance of the catalytic effect of the substrate [82]. 
(a)

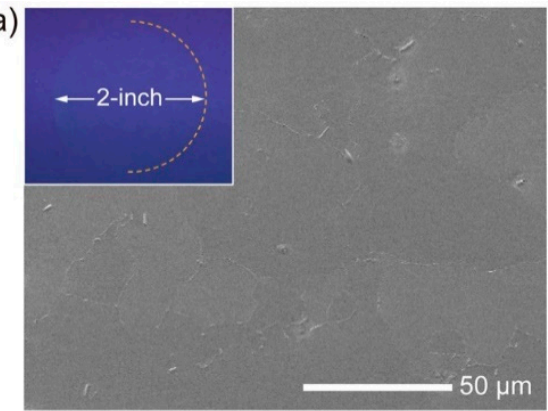

(c)

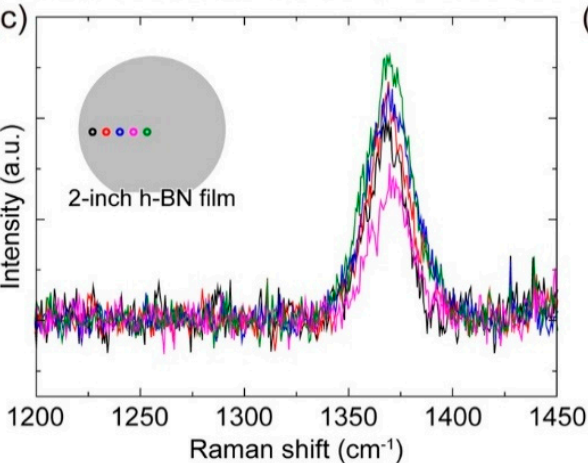

(b)
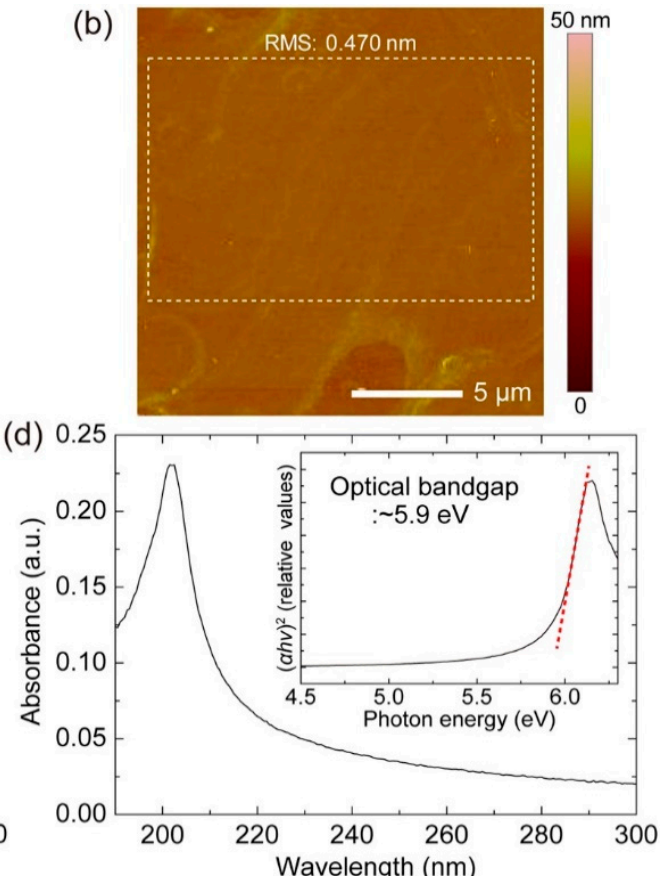
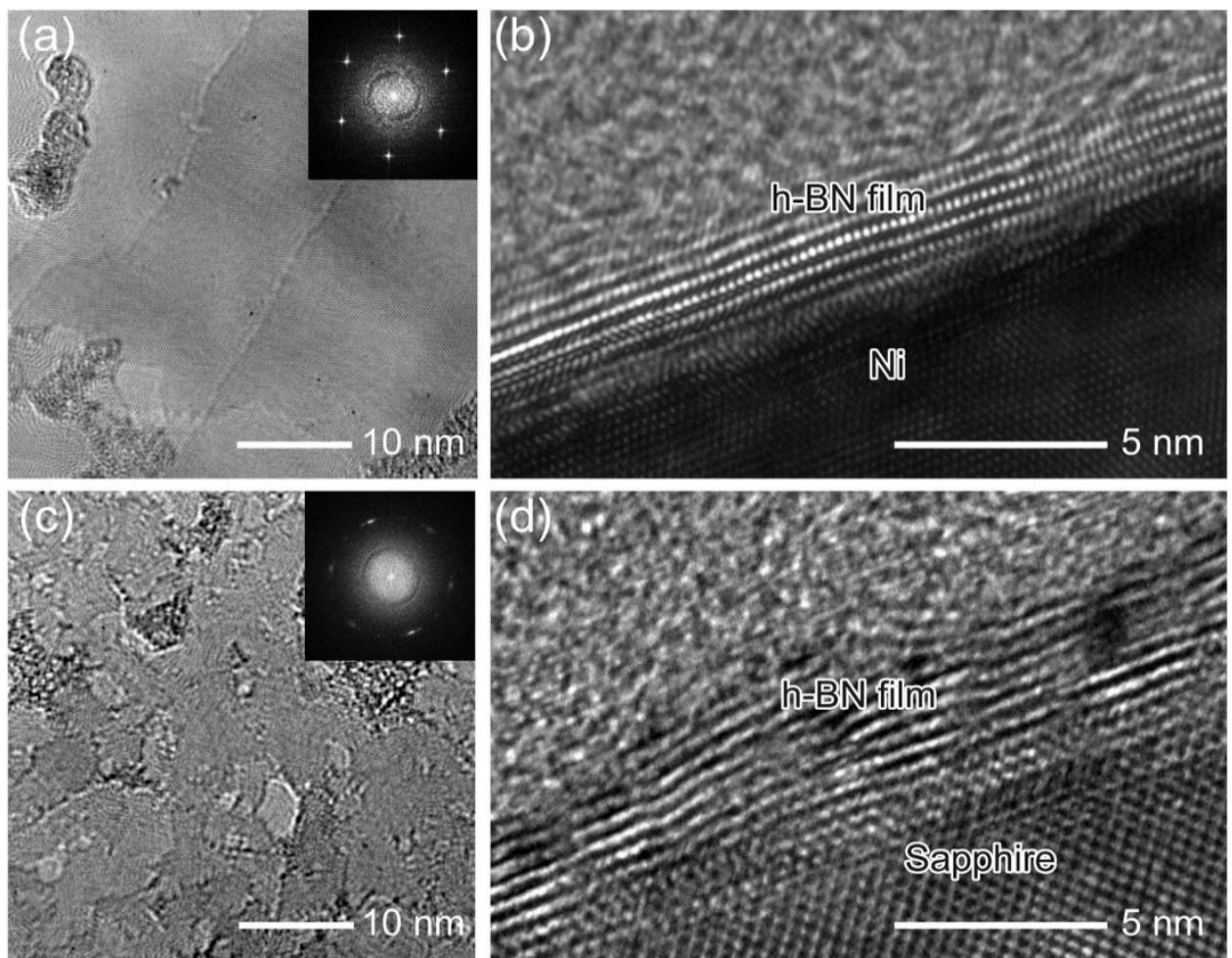

Figure 4. On top: CVD grown h-BN film on Ni (111). (a) SEM, (b) AFM, (c) Raman, (d) UV-Vis characterizations. On bottom: HR-TEM characterization of h-BN grown on $\mathrm{Ni}$ (111) (a) and sapphire (c). Cross-sectional HR-TEM of h-BN on Ni (111) (b) and sapphire (d). Copyright 2019, with permission of [82].

Pulsed laser deposition is a promising technique for the growth of extended films on different types of substrates. The advantage of this method is the possibility of covering a surface, regardless of the substrate. This property allows the growth of BN films on different types of materials, according to the specific applications. Acacia et al. [83] investigated the role of substrate temperature on BN quality, keeping the laser fluence constant at $1.35 \mathrm{~J} \mathrm{~cm}^{-2}$. The experiment was carried out in a high 
vacuum chamber $\left(<10^{-4} \mathrm{~Pa}\right)$ by exposing a rotating $\mathrm{BN}$ target to a $\mathrm{KrF}$ laser irradiation and using $<111>$ c-Si and Corning glass as substrates. Two substrate temperatures, mainly at 25 and $600{ }^{\circ} \mathrm{C}$, were analyzed [83]. The content of nitrogen at $600{ }^{\circ} \mathrm{C}$ decreased, and an excess of the metallic boron phase appeared. Moreover, the films showed both the presence of c-BN and h-BN phases in a largely disordered structure [83].

With the perspective of substituting Ag single crystals with less expensive Ag thin film as a suitable substrate for BN deposition, Velazquez et al. [84] deposited good quality h-BN single layers on $\mathrm{Ag}(111) / \mathrm{SrTiO}_{3}(001)$ substrates (Figure 5).
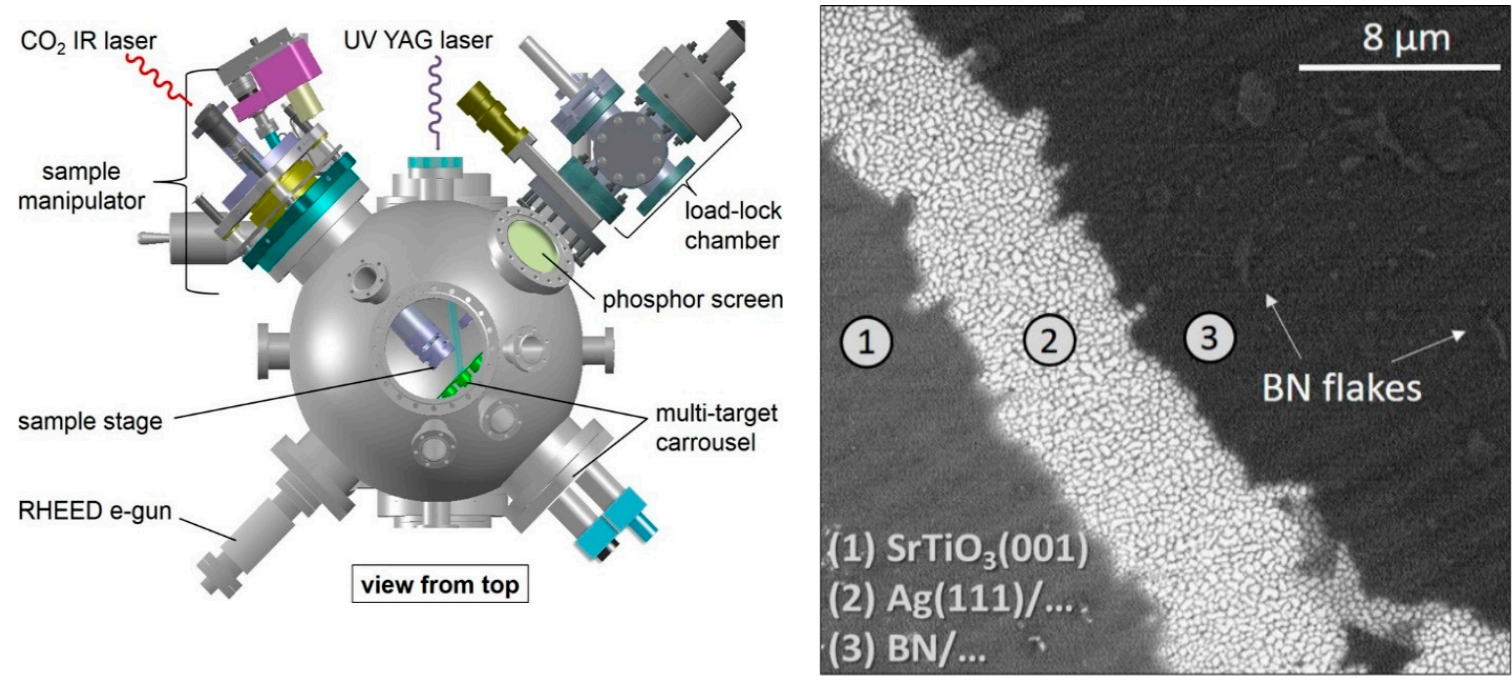

Figure 5. Left: scheme of PLD system. Right: SEM image of h-BN/Ag(111)/SrTiO3(001) deposited by PLD. Copyright 2016, with permission of [84].

The stoichiometric BN films were grown by using the fourth harmonic of an Nd:YAG laser with a fluence between 5 and $6 \mathrm{~mJ} \mathrm{~cm}{ }^{-2}$ and presented a sub-millimeter extension with several flakes on it [84].

A proper choice of the substrate can easily tailor the phase of $\mathrm{BN}$ films. Large and stoichiometric h-BN films have been grown by pulsed layer deposition (PLD) on highly ordered pyrolytic graphite (HOPG). The layered structure consisted of 4 to 6 planes after $5 \mathrm{~s}$ of deposition on $25 \mathrm{~mm}^{2}$ at $700{ }^{\circ} \mathrm{C}$ [85]. Besides, amorphous BN was successfully grown on sapphire (0001). Both crystalline and amorphous materials had high quality and low defects. This route may open the way for film deposition on large surfaces for commercial purposes [85].

Magnetron sputtering is another common approach for physical vapor deposition of films with advantages of simplicity and cost-effectiveness. The method employs a magnetic field to confine the electrons in the region of the sputtering target. A gas (typically $\mathrm{N}_{2}$ or Ar) is ionized by the electron cloud and accelerated towards the cathode. The transfer of momentum ejects the particles from the target, condensing them on the substrate. This technique is considered particularly reliable for thick c-BN and for BCN coatings on cutting tools with high resistance surfaces [86].

Molecular beam epitaxy (MBE) promises to be a valid unconstrained method for high scalable methods, in contrast to CVD which is based on the decomposition of molecular precursors and its strong interaction with the substrates [87]. One of the pioneering works is from Tsai at al. They demonstrated the reliability of plasma assisted MBE methods for the growth of thin BN films on $\mathrm{Ni}$ (111). Ni substrate was preheated at $400{ }^{\circ} \mathrm{C}$ for $20 \mathrm{~min}$ for preliminary cleaning before transfer into an MBE growth machine and then heated up to $900^{\circ} \mathrm{C}$ to remove native oxides and preparation for exposure. High purity boron was evaporated with an electron beam gun at an evaporation rate of $0.9 \mathrm{~A} / \mathrm{h} ; \mathrm{N}$ was provided by a high purity $\mathrm{N}_{2}$ gas flux. The h-BN was grown at a rate of $650 \mathrm{~A} / \mathrm{h}$ and a temperature of $890^{\circ} \mathrm{C}$. Reflection high-energy electron diffraction (RHEED) patterns and X-ray 
diffraction (XRD) have shown that BN films of good quality can be produced [88]. Polycrystalline Ni has also been used for MBE growth of BN thin films. An effusion cell at $1850{ }^{\circ} \mathrm{C}$ for elemental $\mathrm{B}$ and RF plasma source at $350 \mathrm{~W}$ for $\mathrm{N}$ was used as a precursor [89]. Raman spectroscopy measurements confirmed the high crystalline degree of $\mathrm{BN}$ films of hexagonal phase, which exhibit a characteristic sharp peak at $1365 \mathrm{~cm}^{-1}$ ( $G$ band corresponding to the $E_{2 g}$ vibration mode). Despite the homogenous covering of the Ni substrate, atomic force microscopy (AFM) images revealed the presence of ridges with two different features, a wrinkled structure and discontinuous dotted lines. The former defects are likely related to the discrepancy between the $\mathrm{BN}$ and $\mathrm{Ni}$ thermal expansion coefficient but the origin of the latter is still unknown. The process of MBE deposition on poly-Ni started with nucleation of small ramified islands at $730^{\circ} \mathrm{C}$ which changed shape into triangles when the temperature was increased up to $835^{\circ} \mathrm{C}$. The nucleating domains coalesced and evolved into compact films [89].

One of the main advantages of the MBE technique is the possibility to efficiently control the deposition of thin films layer by layer on the atomic scale, without decomposition of the molecular precursors but by assembling the elemental precursors. This deposition control is favorable for $2 \mathrm{D}$ materials, where other techniques such as CVD face the problem of depositing more than a single layer due to the van der Waals forces.

Tonkikh et al. demonstrated the feasibility of achieving precise control of A-B stacking of BN layers. According to the procedure, the Ni (111) substrate was thermally treated at $800{ }^{\circ} \mathrm{C}$. Then followed the deposition of a Ni buffer layer by e-beam evaporation and a single layer of $\mathrm{B}$. Up to 10 high-quality layers were piled up [90] (Figure 6).
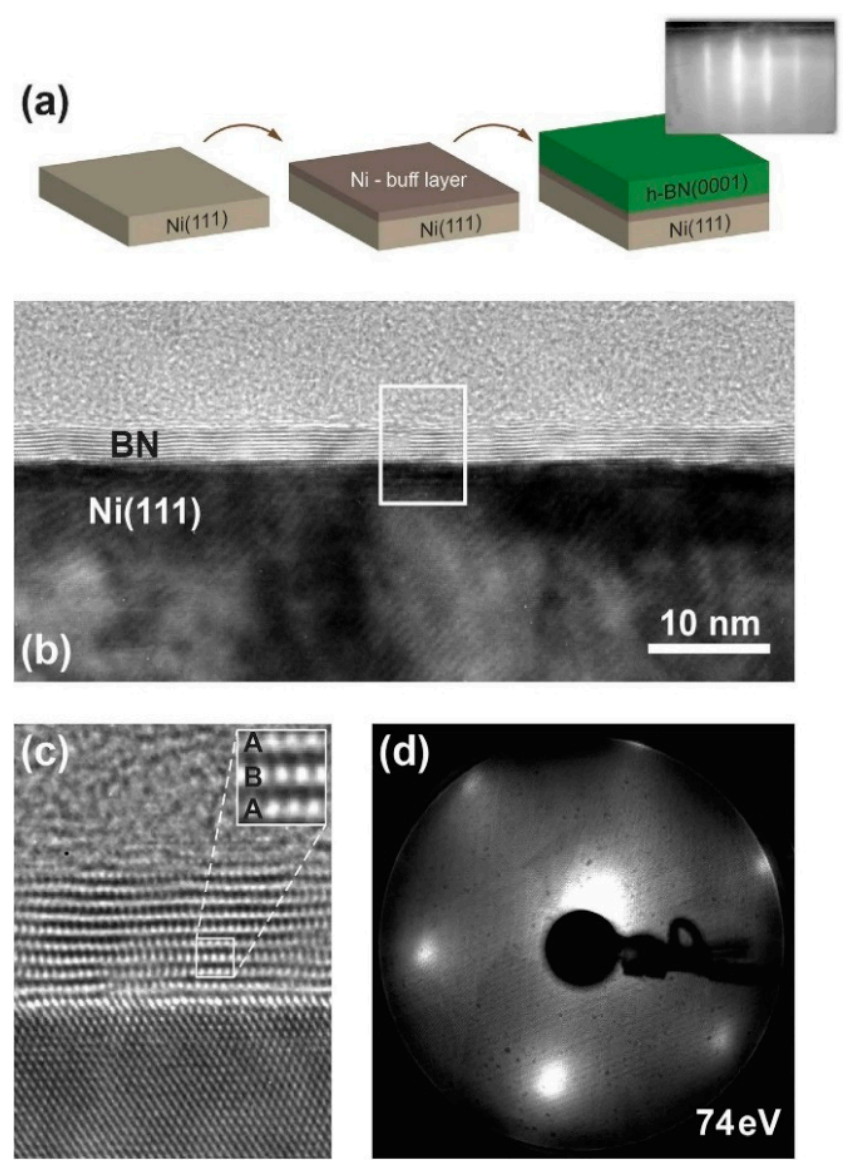

Figure 6. Growth of h-BN on Ni (111) by MBE. (a) deposition of oriented h-BN layer on Ni layer. (b) TEM image of multiple layers. (c) particulars of the layer stacking. (d) LEED image with electron beam energy of $74 \mathrm{eV}$. Copyright 2016, with permission of [90]. 


\subsection{Synthesis Route for BNQD}

The increasing interest in 2-dimensional materials of a few nanometers in size has turned attention onto bottom-up methods from solutions. These methods, being relatively simple and cost- effective, allow the production of 0-D nanomaterials, known as quantum dots. 0-D BN materials (BN dots) are expected to have several high impact applications in photonics, (photo)catalysis, and biomedicine [91]. They have an intrinsic advantage of a high surface/volume ratio.

Most of the mentioned synthesis methods represent valid solutions for the realization of a single layer on substrates, like CVD, or of a few layers through ultrasonication. However, many of the most relevant properties of $\mathrm{BNs}$ are on the nanoscale (on a few nanometers), where the control of the edges and defects become of primary importance. CVD or sonication fails in further reduction of the h-BN monolayer dimensions, preventing access to the properties of BN-based QDs. New specific techniques for the control of size and structure have been developed for this purpose.

Lin et al. reported a method for the fabrication of monolayered BNQDs by exfoliation and disintegration of h-BN flakes (Figure 7). BNQDs of $10 \mathrm{~nm}$ and a direct bandgap of $6.51 \mathrm{eV}$, attributed to the quantum confinement effect, were obtained. The monolayered h-BN presented a blue-green luminescence excitable in the UV region $(365 \mathrm{~nm})$. The authors assigned the QDs' emission to three types of optically active centers: $\mathrm{N}$ vacancies replaced by $\mathrm{C}$ atoms $\left(\lambda_{\mathrm{em}}=423 \mathrm{~nm}\right)$, carbene structures saturating the zig-zag edges $\left(\lambda_{\mathrm{em}}=420 \mathrm{~nm}\right)$ and $\mathrm{BO}_{\mathrm{x}}{ }^{-}(\mathrm{x}=1,2)$ species $\left(\lambda_{\mathrm{em}}=425 \mathrm{~nm}\right)$. The $\mathrm{h}$-BNQDs quantum yield (QY) is $2.5 \%$ [92].

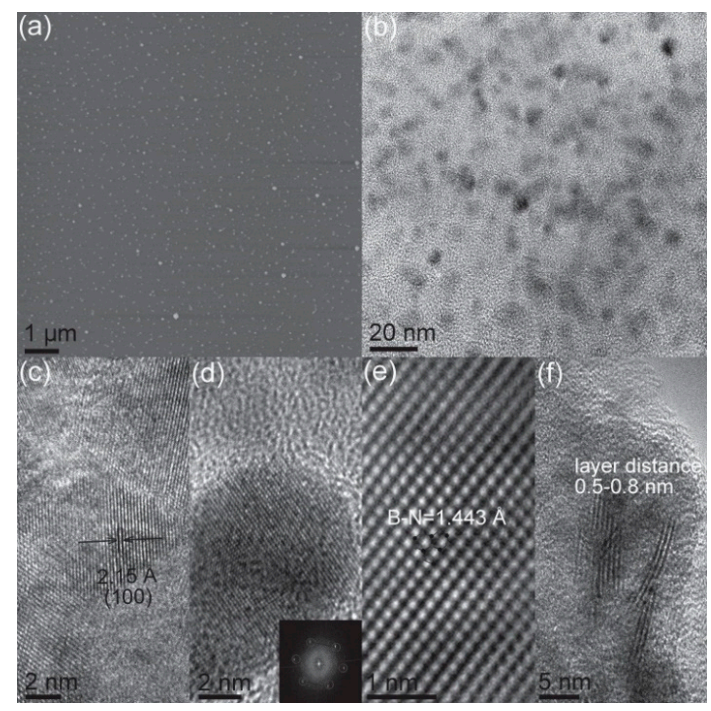

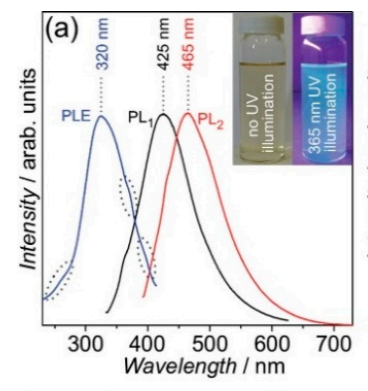
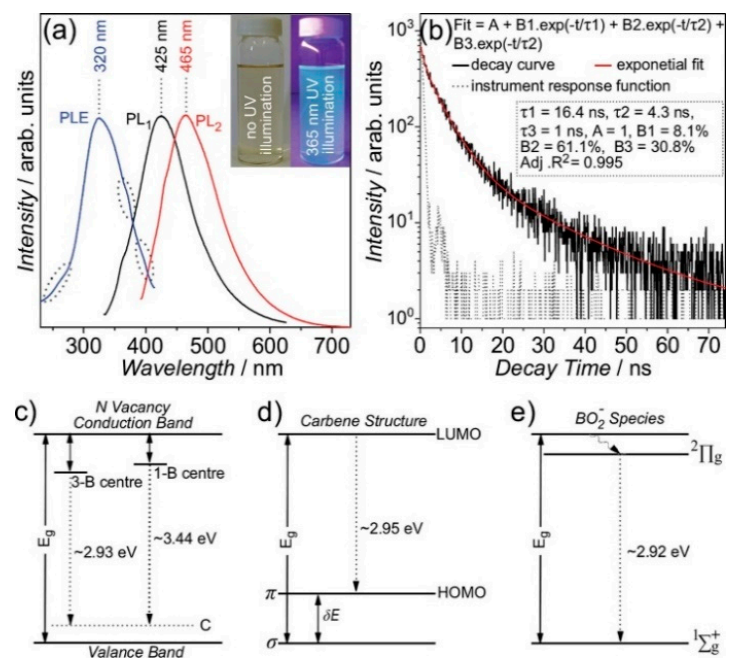

Figure 7. Left: AFM topography image of BNQDs. (b-f) HRTEM images of the BN dots. Right: PLE, PL and time-resolved PL spectra of BNQDs. (c-e) Energy states' attribution to BNQDs luminescence. Copyright 2014, with permission of [92].

Stengl et al. observed similar PL features for samples realized by a high-intensity cavitation procedure. Bulk h-BN was suspended in water and exposed to high intensity ultrasound in a reactor at a pressure of 6 bar for $5 \mathrm{~min}$. The layers were then refluxed in ethylene glycol at $198{ }^{\circ} \mathrm{C}$ under atmospheric pressure for $48 \mathrm{~h}$ [93]. The dots showed a few layers' composition (less than $5 \mathrm{~nm}$ ). The h-BN dots had a broad and asymmetric emission peaked at about $470 \mathrm{~nm}$ upon excitation at $365 \mathrm{~nm}$. At least two components are the source of the emission [93]. Although the authors did not suggest any attribution, the PL appears to be excitation dependent with presumable excitation selectivity of the defects. 
Following a similar approach, Li et al. synthesized BN nanosheets by a sonication treatment of BN powders in dimethylformamide (DMF) for $8 \mathrm{~h}$. After the removal of larger particles by centrifugation, the nanosheets were solvothermally treated in a Teflon-lined autoclave at $200{ }^{\circ} \mathrm{C}$ for $24 \mathrm{~h}$. This method allowed a yield of $21.6 \%$ to be achieved. HRTEM investigations revealed a good crystallinity of BNQDs with a lattice parameter of $0.21 \mathrm{~nm}$. The dimensions of BNQDs depended on the solvothermal treatment time: 10.06, 4.12, $2.41 \mathrm{~nm}$ corresponded to the duration time of 6,12 , and $36 \mathrm{~h}$ respectively [94]. FTIR spectra revealed a strong absorption at 1378 and $800 \mathrm{~cm}^{-1}$ attributed to B-N stretching and B-N bending modes, respectively. The absorption bands at 2931 and $2857 \mathrm{~cm}^{-1}$ were then attributed to the $\mathrm{CH}_{3}$ group of the DMF, demonstrating the presence of solvent residuals on the QDs' surfaces. Besides, the FTIR spectra showed the presence C-(BN), B-O and O-B-O vibrations at 1750-1550, 1150-850, and $750-450 \mathrm{~cm}^{-1}$ and absorption bands at $1386-1450 \mathrm{~cm}^{-1}$, caused by edge oxidation [94]. The PL QY is around $19.5 \%$, a significant improvement compared to previous works as for Lin et al., the PL spectra had an excitation energy dependence. Again, the authors attributed the dominant emission at $395.5 \mathrm{~nm}$ (excited at $375 \mathrm{~nm}$ ) to $\mathrm{BO}_{2}{ }^{-}$centers, with other contributions from carbene edge and 3-B centers [94].

Analogous results were found by Jung et al., who forced the presence of defects on h-BNQDs by striking them with iron nanoparticles and treatment under microwave-sonication in water. As shown by FTIR spectra, the treatment causes hydroxylation of the BNQDs edges as demonstrated by an increase of $-\mathrm{OH}$ stretching mode intensity. XPS spectra exhibited the $\mathrm{B} 1 \mathrm{~s}$ and $\mathrm{N}$ 1s peaks along with $\mathrm{C} 1 \mathrm{~s}$ and $\mathrm{O} 1 \mathrm{~s}$ in both prepared $\mathrm{BN}$ and hydroxylated $\mathrm{BN}$ samples, demonstrating the presence of a carbon and oxygen atom in the structure of the BNQDs [95]. PL spectra have two emissions at $320 \mathrm{~nm}$ (excitable at $280 \mathrm{~nm}$ ) and at $450 \mathrm{~nm}$ (with excitation at $280 \mathrm{~nm}$ and $360 \mathrm{~nm}$ ). The authors attributed the $\mathrm{UV}$ emission to the presence of nitrogen and boron nitride, already seen in bulk h-BN. The emission in the visible range was ascribed to oxygen impurities and decreased in the presence of hydroxylated groups $[95,96]$. Moreover, the PL emission had a pH-dependent modulation, which is typical of defects sites of oxygen on 2D materials [95].

BNQDs grown by a hydrothermal route in water using boron acid and ammonia as precursors showed a visible emission centered at $400 \mathrm{~nm}$. This emission was attributed to a charge-transfer mechanism deriving from the hydroxyl groups, which receive in turn electrons from core nitrogen atoms under UV excitation [47]. Solvothermal synthesis starting with BN nanosheets, revealed that the blue emission is dependent on the solvent polarity [97]. The higher the polarity of the solvent, the more significant is the redshift. The largest redshift was measured in smaller BNQDs (about $2 \mathrm{~nm}$ in size) which excluded any quantum confinement effect. On the contrary, the PL shift should be connected to chemical species or defects in the QDs structures. As reported by Liu et al., the content of oxygen resulting from the higher polarity solvent (NMP in this case) is responsible for emission at larger wavelengths [97].

The origin of BNQDs luminescence has been supposed to originate from the presence of chemical species attached to the surface. The bottom-up synthesis methods, employing an organic solvent or carbon-based precursors can promote the functionalization of BN nanosheets, which in turn display new emissions in the visible range.

The -OH groups at the surfaces of BNQDs, grown by hydrothermal methods, can be exploited to selectively detect metal ions for biological labelling or fluorescent probes purposes. Huo at al. synthesized $\mathrm{OH}$ rich QDs by a hydrothermal route [98]. As shown in Figure 8, upon the addition of $\mathrm{Fe}^{3+}$ ions, the BNQDs underwent a strong fluorescence quenching, under UV excitation. This effect was not reproduced with other ions, such as $\mathrm{Al}^{3+}, \mathrm{Cd}^{2+}, \mathrm{Cu}^{2+}, \mathrm{Co}^{2+}, \mathrm{Pb}^{2+}, \mathrm{Fe}^{2+}, \mathrm{Mn}^{2+}, \mathrm{Ba}^{2+}, \mathrm{Ni}^{2+}, \mathrm{Hg}^{2+}$, and $\mathrm{Ag}^{+}$. The authors attributed the phenomenon to the strong binding affinity of electron-deficient $\mathrm{Fe}^{3+}$ to the electron-rich hydroxyl groups [98]. 
(a)

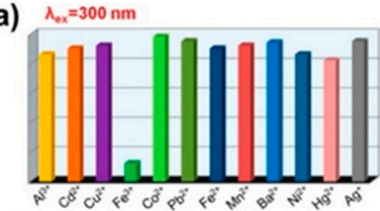

(c)

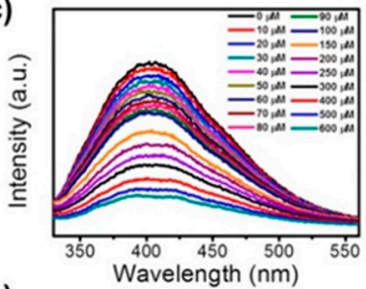

(e)

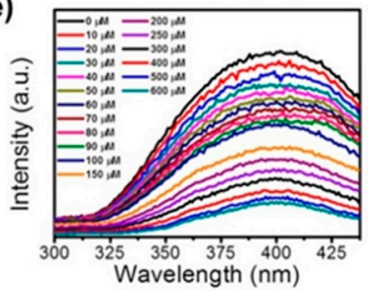

(b)

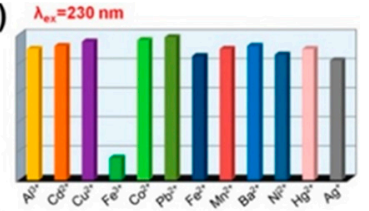

(d)

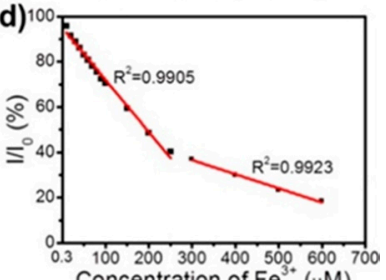

(f) 100

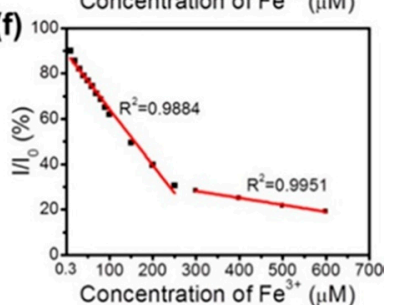

Figure 8. Hydrothermal synthesis route of BNQDs with boric acid and melamine. PL response of BNQDs measured by addition of different metal ions with a concentration of $200 \mu \mathrm{M}$ at the excitation wavelength of 300 and $230 \mathrm{~nm}$, respectively. Copyright 2017, with permission of ref. [98].

Most of the BNQDs exhibit a low quantum yield, which is highly dependent on the synthesis process. Lei at al. achieved an absolute QY of $8.6 \%$ with their BNQDs realized in DMF and DMSO (dimethyl sulfoxide) after exfoliation [51]. Fan et al. demonstrated the efficacy of microwave irradiation over solvothermal methods, in terms of energy and time-saving [99]. The nanoplates of BN obtained by sonication in DMF were irradiated under microwave at a power of $500 \mathrm{~W}$ at $150{ }^{\circ} \mathrm{C}$ for $10 \mathrm{~min}$. The BNQDs, with an average size of $1.98 \mathrm{~nm}$, had a strong emission peaked at $426 \mathrm{~nm}$ and QY $=23.44 \%$, measured using quinine hemisulfate monohydrate as the reference [99].

A QY of $32 \%$ was measured for blue-emitting h-BNQDs, synthesized by a hydrothermal process by Dehghani et al. [100]. After further surface passivation using $P^{2} G_{200}$, the h-BNQDs displayed an increase of QY up to 38\% (again measured by using quinine sulfate as reference) and a slight redshift. The effect of surface passivation was analyzed by FTIR and XPS measurements. Pristine and functionalized samples presented similar chemical species, corresponding to B-O, B-N and oxygen rich functional groups (derived from the exfoliation process). The functionalization process seemed to alter the surface chemical composition favoring the formation of nitrile groups, thereby causing a luminescence redshift [100].

More recently, BNQDs were successfully produced by a hydrothermal route, employing boric acid and ammonia $\left(\mathrm{H}_{3} \mathrm{BO}_{3}: \mathrm{NH}_{3}=1: 6\right)$ at $200{ }^{\circ} \mathrm{C}$ for $10 \mathrm{~h}$ [101]. The dots, with an average dimension of about $10 \mathrm{~nm}$, did not display a pure B-N structure. On the contrary, FTIR, XPS spectra, and XRD patterns show a clear presence of $\mathrm{B}-\mathrm{O}, \mathrm{B}-\mathrm{N}-\mathrm{O}$ and $\mathrm{N}-\mathrm{H}$ bonds and a non-negligible percentage (around $5.5 \%$ ) of unreacted boric acid. Further thermal treatments up to $300{ }^{\circ} \mathrm{C}$ increase the contribution of the B-O component as an effect of the oxidation process. The obtained nanoparticles presented a boron-oxynitride (BOND) network without carbon as contaminant agent [101]. UV-Vis spectra of the BOND particles had four contributions at 220, 265, 308, and $412 \mathrm{~nm}$. The energy band gap was measured at $5.03 \mathrm{eV}$, lower than the $5.81 \mathrm{eV}$ of BN sheets [102], which increased under high temperature treatment due to the reduction of $\mathrm{OH}$ groups. The bands at 220 and $265 \mathrm{~nm}$ are not optically active, whereas the excitations at 308 and $412 \mathrm{~nm}$ produce an emission between $350 \mathrm{~nm}$ and $600 \mathrm{~nm}$. 3D PL excitation-emission-intensity spectra revealed the dual nature (two-color emission) of BOND luminescence, with two maxima at $390 \mathrm{~nm}$ and $470 \mathrm{~nm}$ (Figure 9) [101]. 

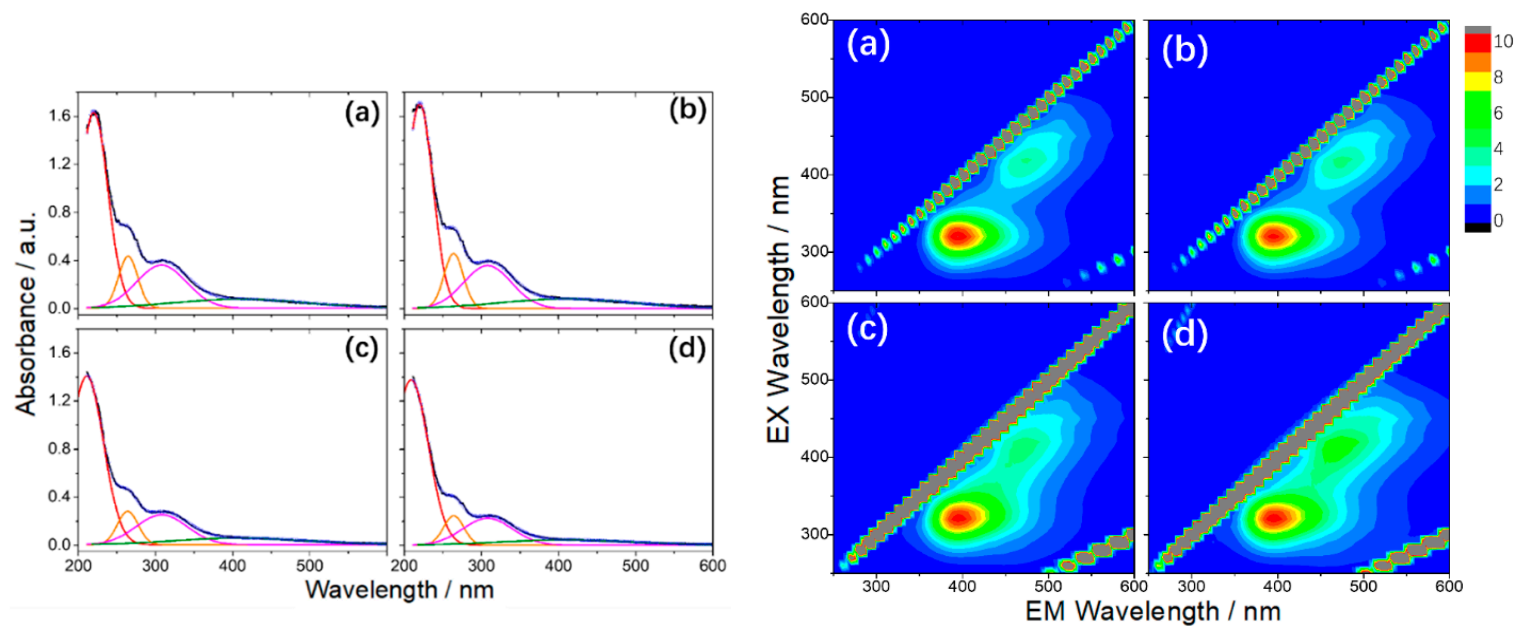

Figure 9. On the left: The UV-Vis absorption spectra and corresponding Gaussian fitting from (a) as prepared, (b) $100{ }^{\circ} \mathrm{C}$, (c) $200{ }^{\circ} \mathrm{C}$, and (d) $300{ }^{\circ} \mathrm{C}$ BONDs (in water, $0.1 \mathrm{mg} \mathrm{mL}^{-1}$ ). On the right: 3D PL excitation-emission-intensity spectra of (a) BONDs, (b) $100{ }^{\circ} \mathrm{C}$, (c) $200{ }^{\circ} \mathrm{C}$, and (d) $300{ }^{\circ} \mathrm{C}$ (in water, 0.1 $\mathrm{mg} \mathrm{mL}^{-1}$ ). Copyright 2019, with permission of ref. [101].

Table 1 lists a summary of the most relevant results. The absolute efficiency of BNQDs is generally below $10 \%$. The higher QYs are measured for some BNQDs produced by employing precursors bearing carbon atoms, which end up doping the BN structure. Furthermore, many of them report a QY obtained through the use of a standard as reference rather than an absolute integrating measurement $[94,99,100,103,104]$ which could in principle provide an overestimation of the luminescence yield [105]. Carbon and oxygen doping inevitably influences the emission mechanisms and their spectral characteristics, according to modalities not yet investigated.

Table 1. Dependence of BNQDs structural and optical properties on the growth process. (a) boron source; (b) nitrogen source; (c) carbon source.

\begin{tabular}{|c|c|c|c|}
\hline Precursors & Growth Conditions & Structure/Quantum Yield & Ref \\
\hline $\begin{array}{l}\text { (a) } \mathrm{NaBH}_{4} \\
\text { (b) } \mathrm{CO}\left(\mathrm{NH}_{2}\right)_{2} \\
\text { (c) } \mathrm{CH}_{5} \mathrm{~N}_{3}, \mathrm{HCl}\end{array}$ & $\begin{array}{l}\text { Ball milling in a eutectic mixture } \\
\text { of } \mathrm{LiCl} / \mathrm{KCl} \text { and then treated at } \\
\quad 700^{\circ} \mathrm{C} \text { for } 2 \mathrm{~h}\end{array}$ & $\begin{array}{c}\mathrm{C}, \mathrm{N} \text {-doped h-BNQDs (BCNO) nanoparticles with } \\
\text { tunable luminescence from blue to green. } \\
\text { a/b/c }=1 / 10 / 0,1 / 0 / 1,1 / 0 / 15,1 / 0 / 10,1 / 0 / 15 \\
\text { QY of } 23 \%, 16 \%, 26 \%, 11 \% \text {, and } 5.6 \%\end{array}$ & [103] \\
\hline $\begin{array}{l}\text { (a) } \mathrm{B}(\mathrm{OH})_{3} \\
\text { (b) } \mathrm{CO}\left(\mathrm{NH}_{2}\right)_{2} \\
\text { (c) } \mathrm{PEG}\end{array}$ & $\begin{array}{l}\text { Calcination at } 750^{\circ} \mathrm{C} \text { for } 1 \mathrm{~h} \text { and } \\
\text { ultrasonic treatment at } 40 \mathrm{kHz} \\
\text { for } 3 \mathrm{~h}\end{array}$ & $\begin{array}{l}\text { BCNO QDs with a mean size of } 10.1 \mathrm{~nm} \text {. } \\
\text { Broad luminescence with two components at } \\
\qquad 400 \mathrm{~nm} \text { and } 500 \mathrm{~nm} \text {. } \\
\text { QY }=19.9 \%\end{array}$ & [104] \\
\hline $\begin{array}{c}\text { (a) } \mathrm{H}_{3} \mathrm{BO}_{3} \\
\text { (b) } \mathrm{CO}\left(\mathrm{NH}_{2}\right)_{2} \\
\left.\text { (c) } \mathrm{PEG} \mathrm{M}_{\mathrm{W}}=20000\right)\end{array}$ & $\begin{array}{l}\text { Calcination of the raw materials } \\
\text { mixture at } 800{ }^{\circ} \mathrm{C} \text { for } 30 \mathrm{~min}\end{array}$ & $\begin{array}{l}\text { BCNO with tunable luminescence from blue to red } \\
\text { with atomic ratio } \mathrm{B} / \mathrm{N}=0.2,0.3,0.4,0.5 ; \mathrm{B} / \mathrm{C}=0.5 \\
\qquad \mathrm{QY}=9.3 \%, 20 \%, 17 \%, 5.2 \%\end{array}$ & [106] \\
\hline $\begin{array}{l}\text { (a) } \mathrm{H}_{3} \mathrm{BO}_{3} \\
\text { (b) } \mathrm{CO}\left(\mathrm{NH}_{2}\right)_{2} \\
\text { (c) } \mathrm{C}_{6} \mathrm{H}_{8} \mathrm{O}_{7}\end{array}$ & $\begin{array}{l}\text { Microwave treatment at } 800 \mathrm{~W} \\
\text { for } 40 \mathrm{~s} \text { after solvent evaporation }\end{array}$ & $\begin{array}{c}\text { BCNO dots with tunable luminescence from blue } \\
\text { to red. Molar ratio a/b/c }=1 / 1 / 2,1 / 1 / 1,1 / 2 / 1,1 / 2 / 2 \text {, } \\
1 / 1 / 0.5,1 / 0.5 / 1,1 / 0 / 1 \\
\text { QY }=50.9 \%, 40.0 \%, 7.5 \%, 19.9 \%, 23.2 \%, 41.2 \%, 3.5 \%\end{array}$ & [107] \\
\hline $\begin{array}{l}\text { (a) } \mathrm{B}(\mathrm{OH})_{3} \\
\text { (b) } \mathrm{CO}\left(\mathrm{NH}_{2}\right)_{2} \\
\text { (c) } \mathrm{C}_{6} \mathrm{H}_{12} \mathrm{O}_{6}\end{array}$ & $\begin{array}{l}\text { Microwave treatment at } 800 \mathrm{~W} \\
\text { for } 10 \mathrm{~min}\end{array}$ & $\begin{array}{l}\text { BCNO particles of } 2 \mathrm{~nm} \text { in size } \\
\text { Blue emission peaked at } 450 \mathrm{~nm} \text { with } \mathrm{QY}=27.1 \%\end{array}$ & [108] \\
\hline $\mathrm{B}(\mathrm{OH})_{3}$ & $\begin{array}{l}\text { Annealing at } 800^{\circ} \mathrm{C} \text { for } 5 \mathrm{~h} \text { and } \\
\text { hydrothermal treatment with } \\
\mathrm{NH}_{3}(\mathrm{pH}=10) \text { at } 100^{\circ} \mathrm{C} \text { for } 6 \mathrm{~h} \\
\text { and sonication for } 2 \mathrm{~h}\end{array}$ & $\begin{array}{l}\text { BCNO nanoparticles with average size of } 4.0 \mathrm{~nm} \text {. } \\
\text { PL emission at } 410 \mathrm{~nm} \text { with } \mathrm{QY}=5 \%\end{array}$ & [109] \\
\hline
\end{tabular}


Table 1. Cont.

\begin{tabular}{|c|c|c|c|}
\hline Precursors & Growth Conditions & Structure/Quantum Yield & Ref \\
\hline $\begin{array}{c}\text { (a) } \mathrm{B}(\mathrm{OH})_{3} \\
\text { (b) } \mathrm{CO}\left(\mathrm{NH}_{2}\right)_{2} \\
\text { (c) } \mathrm{PEG}\left(\mathrm{M}_{\mathrm{W}}=20000\right)\end{array}$ & $\begin{array}{l}\text { Calcination at } 700-900^{\circ} \mathrm{C} \text { for } \\
\quad 30-60 \mathrm{~min}\end{array}$ & $\begin{array}{l}\mathrm{BCNO}(\mathrm{t}-\mathrm{BN}) \text { nanoparticles of } 5 \mathrm{~nm} \text { in size. } \\
\text { Tunable luminescence in correspondence of } \\
\text { different c/a ratios. External QY }=79 \% \\
\left(\lambda_{\mathrm{em}}=469 \mathrm{~nm}\right) ; 76 \%\left(\lambda_{\mathrm{em}}=520 \mathrm{~nm}\right) ; 53 \%( \\
\left.\quad \lambda_{\mathrm{em}}=542 \mathrm{~nm}\right) ; 10 \%\left(\lambda_{\mathrm{em}}=571 \mathrm{~nm}\right)\end{array}$ & [110] \\
\hline BN powder & $\begin{array}{l}\text { Sonication of BN powder in } \\
\text { DMF for } 8 \mathrm{~h} \text { and solvothermal } \\
\text { treatment at } 200^{\circ} \mathrm{C} \text { for } 8 \mathrm{~h}\end{array}$ & $\begin{array}{l}\text { BCN nanoparticles lower than } 4 \mathrm{~nm} \\
\text { PL emission peaked at } 396 \mathrm{~nm} \text {, tunable down to } \\
450 \mathrm{~nm} \text {. } \\
\text { QY }=19.5 \%\left(\lambda_{\mathrm{ex}}=330 \mathrm{~nm}\right)\end{array}$ & [94] \\
\hline BN powder & $\begin{array}{l}\text { Sonication of BN powder in } \\
\text { DMSO or DMF for } 8 \mathrm{~h}\end{array}$ & $\begin{array}{l}\text { BNO nanoparticles of } 2.5 \mathrm{~nm} \text {. } \\
\text { Blue PL emission peaked at } 442 \mathrm{~nm} \text {. } \\
\quad \mathrm{QY}=8.6 \%\left(\lambda_{\mathrm{ex}}=360 \mathrm{~nm}\right)\end{array}$ & [51] \\
\hline BN powder & $\begin{array}{l}\text { Sonication of BN powder in } \\
\text { EtOH, DMF, NMP for } 3 \mathrm{~h} \text { and } \\
\text { solvothermal treatment at } 180 \\
{ }^{\circ} \mathrm{C} \text { for } 10 \mathrm{~h}\end{array}$ & $\begin{array}{c}\text { BNCO dots. } \\
\text { Blue-green emission } \\
\text { EtOH: } 4 \mathrm{~nm} ; \mathrm{QY}=12.6 \% \\
\text { DMF: } 2.8 \mathrm{~nm} ; \mathrm{QY}=16.4 \% \\
\text { NMP: } 2 \mathrm{~nm} \mathrm{QY}=21.3 \%\end{array}$ & [97] \\
\hline
\end{tabular}

\section{Summary}

What emerges from this review is that boron nitride-based systems are still far from having been comprehensively studied and their properties unveiled. BN in its 2-D and 0-D forms is much less understood in comparison to graphene. The BN system turns out to be an extremely stable material, both chemically and thermally. It presents interesting applicative perspectives in electronics as an insulator on a nanometric scale and can be easily interfaced with its conductive counterpart, graphene. Up to now, the possibilities of practical applications extend to very varied fields, from mechanics to optics. However, from careful observation of the experimental results, the exploitation of the mechanical and thermal properties is much more convincing. It is worth emphasizing, once again that the recent development of materials based on BN nanotubes for thermal applications are not addressed in this brief review.

The deposition processes of single or few layers on large regions remain at the level of basic experiments. Although some methods are progressing in terms of material quality and extensions, the most favorable substrates and the choice of the most common precursors are still under study.

Furthermore, defect control seems to be far from being fully understood. We have seen how researchers apply an approach which is like that of carbon-based materials. The target is to obtain 0dimensional systems as visible emitters for uses in lighting or diagnostics. It appears, however, virtually impossible to obtain a homogeneous structure of $\mathrm{BN}$, without foreign atoms which partially modify the structure. The top-down methods allow, in principle, to derive BN nanosheets by ultrasonication. It is, however, very complicated to be able to control the exfoliation process down to the monolayer and the process yield is still rather poor for scaling up. Bottom-up solution systems have given the most encouraging results in terms of optical emissions. However, the emissions are due to defects or foreign atoms introduced during the process which originate from precursors and solvents. Hydrothermal routes, on the other hand, contribute to the functionalization of the BN system with $\mathrm{OH}$ groups. Even if the functionalizing groups or the doping atoms contribute to the reduction of the optical band gap and the emission in the visible range, the doping mechanisms are not yet clear. The theoretical studies highlight the nature of the most probable $\mathrm{BN}$ defects which are vacancies of $\mathrm{B}$ or $\mathrm{N}$, interstitial defects, or chemical groups derived from interaction with the growth environment, as in the case of BOs.

However, until now, no systematic study aimed at labelling each of the BNQDs emissions has been carried out. Many of the experimental works are limited to reporting multiple recipes for the growth of BNQDs, measuring visible emissions without an in-depth study of the growth process impact on the final performance of the $\mathrm{BN}$. 
Most of the works on BN are devoted to realizing dots of high emission in the visible and with high quantum yields. Unfortunately, a description of BN dot radiative recombinations is still lacking. It is also not clear what the effect is of the substitution or elimination of some atoms.

We believe that it is essential to perform specific studies to assess the origin of the emission properties of fluorescent dots. In a scenario where research is still in its early stages, this would allow full exploitation of the potential of BN-based low-dimensional materials.

Author Contributions: The manuscript was written through contributions of all authors. All authors have given approval to the final version of the manuscript.

Funding: This research received no external funding.

Conflicts of Interest: The authors declare no conflict of interest.

\section{Abbreviations}

$\begin{array}{ll}\text { h-, c-, r-, w- } & \text { hexagonal, cubic, rhombohedral, wurzite } \\ \text { BCNO } & \text { C, N-doped h-BNQDs } \\ \text { BOND } & \text { boron-oxynitride } \\ \text { BN } & \text { boron nitride } \\ \text { BNQD } & \text { boron nitride quantum dots } \\ \text { CNT } & \text { carbon nanotubes } \\ \text { CVD } & \text { chemical vapor deposition } \\ \text { DFT } & \text { density functional theory } \\ \text { DMF } & \text { dimethylformamide } \\ \text { DMSO } & \text { dimethyl sulfoxide } \\ \text { DUV } & \text { deep ultraviolet } \\ \text { EELS } & \text { electron energy loss spectroscopy } \\ \text { HOMO } & \text { highest occupied molecular orbital } \\ \text { LEED } & \text { low-energy electron diffraction } \\ \text { LUMO } & \text { lowest occupied molecular orbital } \\ \text { MBE } & \text { molecular beam epitaxy } \\ \text { NMP } & \text { N-Methyl-2-pyrrolidone } \\ \text { NT } & \text { nanotubes } \\ \text { PL } & \text { photoluminescence } \\ \text { PLD } & \text { pulsed laser deposition } \\ \text { PLE } & \text { photoluminescence excitation } \\ \text { QD } & \text { quantum dot } \\ \text { QY } & \text { quantum yield } \\ \text { SAED } & \text { selected area electron diffraction } \\ \text { TEM } & \text { Transmission electron microscopy } \\ & \end{array}$

\section{References}

1. Mishra, N.S.; Saravanan, P. A Review on the Synergistic Features of Hexagonal Boron Nitride (White Graphene) as Adsorbent-Photo Active Nanomaterial. ChemistrySelect 2018, 3, 8023-8034. [CrossRef]

2. Yu, S.; Wang, X.; Pang, H.; Zhang, R.; Song, W.; Fu, D.; Hayat, T.; Wang, X. Boron nitride based materials for the removal of pollutants from aqueous solutions: A review. Chem. Eng. J. 2017, 333, 343-360. [CrossRef]

3. Liu, X.; Chen, X.; Ma, H.A.; Jia, X.; Wu, J.; Yu, T.; Wang, Y.; Guo, J.; Petitgirard, S.; Bina, C.R.; et al. Ultrahard stitching of nanotwinned diamond and cubic boron nitride in C2-BN composite. Sci. Rep. 2016, 6, 30518. [CrossRef] [PubMed]

4. Chubarov, M.; Pedersen, H.; Hogberg, H.; Jensen, J.; Henry, A. Growth of High Quality Epitaxial Rhombohedral Boron Nitride. Cryst. Growth Des. 2012, 12, 3215-3220. [CrossRef]

5. Liu, Y.; Zhan, G.D.; Wang, Q.; He, D.; Zhang, J.; Liang, A.; Moellendick, T.E.; Zhao, L.; Li, X. Hardness of Polycrystalline Wurtzite boron nitride(wBN) compacts. Sci. Rep. 2019, 9, 10215. [CrossRef] 
6. Pan, Z.; Sun, H.; Zhang, Y.; Chen, C. Harder than Diamond: Superior Indentation Strength of Wurtzite BN and Lonsdaleite. PRL 2009, 102, 055503. [CrossRef]

7. Lin, Y.; Connell, J.W. Advances in 2D boron nitride nanostructures: Nanosheets, nanoribbons, nanomeshes, and hybrids with graphene. Nanoscale 2012, 4, 6908-6939. [CrossRef]

8. Pakdel, A.; Bando, Y.; Golberg, D. Nano boron nitride flatland. Chem. Soc. Rev. 2014, 43, 934-959. [CrossRef]

9. Kostoglou, N.; Polychronopoulou, K.; Rebholz, C. Thermal and chemical stability of hexagonal boron nitride (h-BN) nanoplates. Vacuum 2015, 112, 42-45. [CrossRef]

10. Li, L.H.; Cervenka, J.; Watanabe, K.; Taniuguchi, T.; Chen, Y. Strong oxidation resistance of atomically thin atomically thin boron nitride nanosheets. ACS Nano 2014, 8, 1457-1462. [CrossRef]

11. Cai, Q.; Scullion, D.; Gan, W.; Falin, A.; Zhang, S.; Watanabe, K.; Taniguchi, T.; Chen, Y.; Santos, E.J.G.; Li, L.H. High thermal conductivity of high-quality monolayer boron nitride and its thermal expansion. Sci. Adv. 2019, 5, eaav0129. [CrossRef] [PubMed]

12. Cassabois, G.; Valvin, P.; Gil, B. Hexagonal boron nitride is an indirect bandgap semiconductor. Nat. Photon. 2016, 10, 262. [CrossRef]

13. Wickramaratne, D.; Weston, L.; Van de Walle, C.G. Monolayer to Bulk Properties of Hexagonal Boron Nitride. J. Phys. Chem. C 2018, 122, 25524-25529. [CrossRef]

14. Elias, C.; Valvin, P.; Pelini, T.; Summerfield, A.; Mellor, C.J.; Eaves, L.; Foxon, C.T.; Beton, P.H.; Novikov, S.V.; Gil, B.; et al. Direct band-gap crossover in epitaxial monolayer boron nitride. Nat. Commun. 2019, 10, 2639. [CrossRef] [PubMed]

15. Corso, M.; Auwarter, W.; Muntwiler, M.; Tamai, A.; Greber, T.; Osterwalder, J. Boron nitride nanomesh. Science 2004, 303, 217-220. [CrossRef] [PubMed]

16. Berner, S.; Corso, M.; Widmer, R.; Groening, O.; Laskowski, R.; Blaha, P.; Schwarz, K.; Goriachko, A.; Over, H.; Gsell, S.; et al. Boron Nitride, NAnomesh: Funcionality from a Corrugated Monolayer. Angew. Chem. Int. Ed. 2007, 46, 5115-5119. [CrossRef]

17. Goriachko, A.; He, Y.; Knapp, M.; Over, H.; Corso, M.; Brugger, T.; Berner, S.; Osterwalder, J.; Greber, T. Self-Assembly of a Hexagonal Boron Nitride Nanomesh on Ru (0001). Langmuir 2007, 23, 2928-2931. [CrossRef]

18. Cun, H.; Seitsonen, A.P.; Roth, S.; Decurtins, S.; Liu, S.X.; Osterwalder, J.; Greber, T. An electron acceptor molecule in a nanomesh: $\mathrm{F}_{4}$ TCNQ on h-BN/Rh (111). Surf. Sci. 2018, 678, 183-188. [CrossRef]

19. Jiang, H.X.; Lin, J.Y. Hexagonal boron nitride for deep ultraviolet photonic devices. Semicond. Sci. Technol. 2014, 29, 084003. [CrossRef]

20. Song, Y.; Sun, Y.; Shin, D.H.; Yun, K.N.; Song, Y.H.; Milne, W.I.; Lee, C.J. Excellent oxidation endurance of boron nitride nanotube field electron emitters. Appl. Phys. Lett. 2014, 104, 163102. [CrossRef]

21. Maity, A.; Grenadiar, S.J.; Li, J.; Lin, J.Y. Jiang Toward achieving flexible and high sensitivity hexagonal boron nitride neutron detectors. Appl. Phys. Lett. 2017, 111, 033507. [CrossRef]

22. Maity, A.; Grenadiar, S.J.; Li, J.; Lin, J.Y.; Jiang, H.X. Hexagonal boron nitride neutron detectors with high detection efficiencies. J. Appl. Phys. 2018, 123, 044501. [CrossRef]

23. Shankar, R.; Sachs, M.; Francas, L.; Lubert-Perquel, D.; Kerherve, G.; Regoutz, A.; Petit, C. Porous Boron Nitride for Combined $\mathrm{CO}_{2}$ Capture and Photoreduction. J. Mater. Chem. A 2019, 7, 23931-23940. [CrossRef]

24. Wang, N.; Yang, G.; Wang, H.; Sun, R.; Wong, C.P. Visible Light-Responsive Photocatalytic Activity of Boron Nitride Inorporated Composites. Front. Chem. 2018, 6, 440. [CrossRef] [PubMed]

25. Zhou, C.; Lai, C.; Zeng, G.; Huang, D.; Cheng, M.; Hu, L.; Xiong, W.; Chen, M.; Wang, J.; Yang, Y.; et al. Semiconductor/boron nitride composites: Synthesis, properties, and photocatalysis applications. Appl. Catal. B Environ. 2018, 15, 6-18. [CrossRef]

26. Fredrickson, J.E.; Redanz, W.H. Boron nitride for aerospace applications. Mater. Sci. Res. 1965, 2, $245-260$.

27. Chen, X.; Dmuchowki, C.M.; Park, C.; Fay, C.; Ke, C. Quantitative characterization of structural and mechanical properties of boron nitride nanotubes in high temperature environments. Sci. Rep. 2017, 7, 11388. [CrossRef]

28. Du, A. In silico engineering of grapheme-based van der Waals heterostructured nanohybrids for electronics and energy applications. Comput. Mol. Sci. 2016, 6, 551-570. [CrossRef]

29. Bandyopadhyay, A.; Yamijala, S.S.R.K.C.; Pati, S.K. Tuning the electronic and optical properties of grapheme and botron-nitride quantum dots by molecular charge-transfer interactions: A theoretical study. Phys. Chem. Chem. Phys. 2013, 15, 13881-13887. [CrossRef] 
30. Berseneva, N.; Gulas, A.; Krasheninnikov, A.V.; Nieminen, R.M. Electronic structure of boron nitride sheets doped with carbon from first-principles calculations. Phys. Rev. B 2013, 87, 035404. [CrossRef]

31. Zhao, Y.X.X.; Wang, A.; Wang, X.; Bu, H.; Zhao, M. Tuning the electronic and magnetic properties of triangular boron nitride quantum dots via carbon doping. Physica E 2013, 49, 52-60.

32. Huang, C.; Chen, C.; Zhang, M.; Lin, L.; Ye, X.; Lin, S.; Antonietti, M.; Wang, X. Carbon-doped BN nanosheets for metal-free photoredox catalysis. Nat. Com. 2015, 6, 7698. [CrossRef] [PubMed]

33. Gao, M.; Adachi, M.; Lyalin, A.; Taketsugu, T. Long range functionalization of h-BN monolayer by carbon doping. J. Phys. Chem. C 2016, 120, 15993-16001. [CrossRef]

34. Krepel, D.; Kalikhman-Razvozov, L.; Hod, O. Edge chemistry effects on the structural, electronic and electric response properties od boron nitride quantum dots. J. Phys. Chem. C 2014, 118, 21110-21118. [CrossRef]

35. Shayeganfar, F.; Tabar, M.R.R.; Simchi, A.; Beheshtian, J. Effects of functionalization and side defects on single-photon emission in boron nitride quantum dots. Phys. Rev. B 2017, 96, 165307. [CrossRef]

36. Tran, T.T.; Bray, K.; Ford, M.J.; Toth, M.; Aharonovich, I. Quantum emission form hexagonl boron nitride monolayers. Nat. Nanotechnol. 2016, 11, 37-41. [CrossRef]

37. Tran, T.T.; Elbadawi, C.; Totonjian, D.; Lobo, C.; Grosso, G.; Moon, H.; Englund, D.R.; Ford, M.J.; Aharonovich, I.; Torh, M. Robust multicolor single photon emission from pint defects in hexagonal boron nitride. ACS Nano 2016, 10, 7331-7338. [CrossRef]

38. Attaccalite, C.; Bockstedte, M.; Marini, A.; Rubio, A.; Wirtz, L. Coupling of excitons and defect states in boron-nitride nanostructures. Phys. Rev. B 2011, 88, 144115. [CrossRef]

39. Cheng, G.D.; Zhang, Y.G.; Yan, L.; Huang, H.F.; Huang, Q.; Song, Y.X.; Chen, Y.; Tang, Z. A parametric neutral CBVN center in hexagonal boron nitride monolayer for spin qubit application. Comp. Mater. Sci. 2017, 129, 247-251. [CrossRef]

40. Sajid, A.; Reimers, J.R.; Ford, M.J. Defect states in hexagonal boron nitride: Assignments of observed properties and prediction of properties relevant to quantum computation. Phys. Rev. B 2018, 97, 064101. [CrossRef]

41. Korona, T.; Chojecki, M. Exploring point defects in hexagonal boron-nitrogen monolayers. Int. J. Quantum Chem. 2019, 119, e25925. [CrossRef]

42. Weston, L.; Wickramaratne, D.; Mackoit, M.; Alkauskas, A.; Van de Walle, C.G. Native point defect and impurities in hexagonal boron nitride. Phys. Rev. B 2018, 97, 214104. [CrossRef]

43. Ranjian, P.; Agrawal, S.; Sinha, A.; Rao, T.R.; Balakrishnan, J.; Thakur, A.D. A low-cost non-explosive synthesis of graphene oxide for scalable applications. Sci. Rep. 2018, 8, 12007. [CrossRef] [PubMed]

44. Zhong, J.; Sun, W.; Wei, Q.; Qian, X.; Cheng, H.M.; Ren, W. Efficient and scalable synthesis of highly aligned and compact two-dimensional nanosheet films with record performances. Sci. Rep. 2018, 9, 3484. [CrossRef] [PubMed]

45. Bhimanapati, G.R.; Glavin, N.R.; Robinson, J.A. Semiconductors and Semimetals; Iacopi, F., Boeckl, J.J., Jagadish, C., Eds.; Elsevier: Amsterdam, The Netherlands, 2016; Volume 95, p. 101.

46. Arole, V.M.; Munde, S.V. Fabrication of Nanomaterials by Top-Down and Bottom-Up approaches-An Overview. J. Mater. Sci. 2014, 1, 89-93.

47. Liu, B.; Yan, S.; Song, Z.; Liu, M.; Ji, X.; Yang, W.; Liu, J. One-step synthesis of boron nitride quantum dots: Simple chemistry meets delicate nanotechnology. Chem. Eur. J. 2016, 22, 18899-18907. [CrossRef]

48. Lian, G.; Zhang, X.; Si, H.; Wang, J.; Cui, D.; Wang, Q. Boron Nitride Ultrathin Fibrous Nanonets: One-Step Synthesis and Applications for Ultrafast Adsorption for Water Treatment and Selective Filtration of Nanoparticles. ACS Appl. Mater. Interfaces 2013, 5, 12773-12778. [CrossRef]

49. Radhakrishnan, S.; Das, D.; Samanta, A.; de los Reyes, C.A.; Deng, L.; Alemany, L.B.; Weldeghiorghis, T.K.; Khabashesku, V.N.; Kochat, V.; Jin, Z.; et al. Fluorinated h-BN as a magnetic semiconductor. Sci. Adv. 2017, 3, e1700842. [CrossRef]

50. Tian, Z.; Chen, K.; Sun, S.; Zhang, J.; Cui, W.; Xie, Z.; Liu, G. Crystalline boron nitride nanosheets by sonication-assisted hydrothermal exfoliation. J. Adv. Ceram. 2019, 8, 72-78. [CrossRef]

51. Lei, Z.; Xu, S.; Wan, J.; Wu, P. Facile preparation and multifunctional applications of boron nitride quantum dots. Nanoscale 2015, 7, 18902-18907. [CrossRef]

52. Thangasamy, P.; Santhanam, M.; Sathish, M. Supercritical fluid facilitated disintegration of hexagonal boron nitride nanosheets to quantum dots and its application in cells imaging. ACS Appl. Mater. Interfaces 2016, 8, 18647-18651. [CrossRef] [PubMed] 
53. Novoselov, K.S.; Geim, A.K.; Morozov, S.V.; Jiang, D.; Zhang, Y.; Dubonos, S.V.; Grigorieva, I.V.; Firsov, A.A. Electric field effect in Atomically thin Carbon Films. Science 2004, 306, 666-669. [CrossRef] [PubMed]

54. Huang, Y.; Sutter, E.; Shi, N.N.; Zheng, J.; Tang, T.; Englund, D.; Gao, H.J.; Sutter, P. Reliable Exfoliation of Large-Area high-quality flakes of Graphene and other two-Dimensional materials. ACS Nano 2015, 9 , 10612-10620. [CrossRef] [PubMed]

55. Tang, D.M.; Kvashnin, D.G.; Najmaei, S.; Bando, Y.; Kimoto, K.; Koskinen, P.; Ajayan, P.M.; Yakobson, B.I.; Sorokin, P.B.; Lou, J.; et al. Nanomechanical cleavage of molybdenum disulfide atomic layers. Nat. Commun. 2014, 5, 3631. [CrossRef]

56. Namba, S.; Takagaki, A.; Jimura, K.; Hayashi, S.; Kikuchi, R.; Oyama, S.T. Effects of ball-milling treatment on physicochemical properties and solid base activity of hexagonal boron nitrides. Catal. Sci. Technol. 2019, 9, 302-309. [CrossRef]

57. Deepika, A.; Li, L.H.; Glushenkov, A.M.; Hait, S.K.; Hodgson, P.; Chen, Y. High-Efficient Production of Boron Nitride Nanosheets via an Optimized Ball Milling Process for Lubrication in Oil. Sci. Rep. 2014, 4, 7288. [CrossRef]

58. Lee, D.; Lee, B.; Park, K.H.; Ryu, H.J.; Jeon, S.; Hong, S.H. Scalable Exfoliation process for highly soluble boron nitride nanoplatelets by hydroxide-assisted ball milling. Nanoletters 2015, 15, 1238-1244. [CrossRef]

59. Li, L.H.; Chen, Y.; Behan, G.; Zhang, H.; Petravic, M.; Glushenkova, A.M. Large-scale mechanical peeling of boron nitride nanosheets by low-energy ball milling. J. Mater. Chem. 2011, 21, 11862-11866. [CrossRef]

60. Yurdakul, H.; Goncu, Y.; Durukan, O.; Akay, A.; Seyhan, A.T.; Ay, N.; Turan, S. Nanoscopic characterization of two-dimensional (2D) boron nitride nanosheets (BNNSs) produced by microfluidization. Ceram. Int. 2012, 38, 2187-2193. [CrossRef]

61. Chen, X.; Dobson, J.F.; Raston, C.L. Vortex fluidic exfoliation of graphite and boron nitride. Chem. Commun. 2012, 48, 3703-3705. [CrossRef]

62. Wang, H.; Zhao, Y.; Xie, Y.; Ma, X.; Zhang, X. Recent progress in synthesis of two-dimensional hexagonal boron nitride. J. Semic. 2017, 38, 031003. [CrossRef]

63. Zhang, K.; Feng, Y.; Wang, F.; Yanga, Z.; Wang, J. Two dimensional hexagonal boron nitride (2D-hBN): Synthesis, properties and applications. J. Mater. Chem. C 2017, 5, 11992-12022. [CrossRef]

64. Kim, J.; Kwon, S.; Cho, D.H.; Kang, B.; Kwon, H.; Kim, Y.; Park, S.O.; Jung, G.Y.; Shin, E.; Kim, W.G.; et al. Direct exfoliation and dispersion of two-dimensional materials in pure water via temperature control. Nat. Commun. 2015, 6, 8294. [CrossRef] [PubMed]

65. Xu, Y.; Cao, H.; Xue, Y.; Li, B.; Cai, W. Liquid-Phase Exfoliation of Graphene: An Overview on Exfoliation Media, Techniques, and Challenges. Nanomaterials 2018, 8, 942. [CrossRef] [PubMed]

66. Flint, E.B.; Suslick, K.S. The temperature of cavitation. Science 1991, 253, 1397-1399. [CrossRef] [PubMed]

67. Han, W.; Wu, L.; Zhu, Y.; Watanabe, K.; Taniguchi, T. Structure of chemically derived mono- and few-atomic-layer boron nitride sheets. Appl. Phys. Lett. 2008, 93, 223103. [CrossRef]

68. Coleman, J.N.; Lotya, M.; O'neill, A.; Bergin, S.D.; King, P.J.; Khan, U.; Young, K.; Gaucher, A.; De, S.; Smith, R.J.; et al. Two-Dimensional NAnosheets Produced by Liquid Exfoliaiton of Layered Materials. Science 2011, 331, 568-571. [CrossRef]

69. Shen, J.; He, Y.; Wu, J.; Gao, C.; Keyshar, K.; Zhang, X.; Yang, Y.; Ye, M.; Vajtai, R.; Lou, J.; et al. Liquid phase exfoliation of two-Dimansional Materials by Directly Probilng and Maching Surface Tension Components. Nano Lett. 2015, 15, 5449-5454. [CrossRef]

70. Stengl, V.; Henych, J.; Slusna, M.; Echorchard, P. Ultrasound exfoliation of inorganic analogues graphene. Nanoscale Res. Lett. 2014, 9, 167. [CrossRef]

71. Rafiei-Sarmazdeh, Z.; Jafari, S.H.; Ahmadi, S.J.; Zahedi-Dizaj, S.M. Large-scale exfoliation of hexagonal boron nitride with combined fast quenching and liquid exfoliation strategies. J. Mater. Sci. 2016, 51, 3162-3169. [CrossRef]

72. Kim, D.; Nakajima, S.; Sawada, T.; Iwasaki, M.; Kawauchi, S.; Zhi, C.; Bando, Y.; Golberg, D.; Serizawa, T. Sonication-assisted alcoholysis of boron nitride nanotubes for their sidewalls chemical peeling. Chem. Commun. 2015, 51, 7104-7107. [CrossRef] [PubMed]

73. Ortiz, D.G.; Pochat-Bohatier, C.; Cambedouzou, J.; Bechelany, M.; Miele, P. Exfoliation of Hexagonal Boron Nitride (h-BN) in Liquide Phase by Ion Intercalation. Nanomaterials 2018, 8, 716. [CrossRef] [PubMed]

74. Cao, L.; Emami, S.; Lafdi, K. Large-scale exfoliation of hexagonal boron nitride nanosheets in liquid phase. Mater. Express 2014, 4, 165-171. [CrossRef] 
75. Lin, Y.; Williams, T.V.; Xu, T.B.; Cao, W.; Elsayed-Ali, H.E.; Connell, J.W. Aqueous Dispersions of Few-Layered and Monolayered Hexagonal Boron Nitride Nanosheets from Sonication-Assisted Hydrolysis: Critical Role of Water. J. Phys. Chem. C 2011, 115, 2679-2685. [CrossRef]

76. Bhimanapati, G.R.; Kozuch, D.; Robinson, J.A. Large-scale synthesis and functionalization of hexagonal boron nitride nanosheets. Nanoscale 2014, 6, 11671-11675. [CrossRef]

77. Wang, Y.; Shi, Z.; Yin, J. Boron nitride nanosheets: Large-scale exfoliation in methanesulfonic acid and their composites with polybenzimidazole. J. Mater. Chem. 2011, 21, 11371-11377. [CrossRef]

78. Paffett, M.T.; Simonson, R.J.; Papin, P.; Paine, R.T. Borazine adsorption and decomposition at Pt (111) and Ru (001) surfaces. Surf. Sci. 1990, 232, 286-296. [CrossRef]

79. Nagashima, A.; Teijima, N.; Gamou, Y.; Kawai, T.; Oshima, C. Electronic dispersion relations of monolayer hexagonal boron nitride formed on the Ni (111) surface. Phys. Rev. B 1995, 51, 4606-4613. [CrossRef]

80. Muller, F.; Stowe, K.; Sachdev, H. Symmetry versus Commensurability: Epitaxial Growth of Hexagonal Boron Nitride on Pt (111) From B-Trichloroborazine (ClBNH) 3. Chem. Mater. 2005, 17, 3464-3467. [CrossRef]

81. Chatterjee, S.; Luo, Z.; Acerce, M.; Yates, D.M.; Johnson, A.C.; Sneddon, L.G. Chemical Vapor Deposition of Boron Nitride Nanosheets on metallic Substrates via Decaborane/Ammonia Reactions. Chem. Mater. 2011, 23, 4414-4416. [CrossRef]

82. Jeong, H.; Kim, D.Y.; Kim, J.; Moon, S.; Han, N.; Lee, S.H.; Okello, O.F.N.; Song, K.; Choi, S.; Kim, J.K. Wafer-Scale and selective-area growth of high-quality hexagonal boron nitride on $\mathrm{Ni}$ (111) by metal-organic chemical vapor deposition. Sci. Rep. 2019, 9, 5736. [CrossRef]

83. Acacia, N.; Fazio, E.; Neri, F.; Ossi, P.M.; Trusso, S.; Santo, N. Pulsed laser deposition of boron nitride thin films. Radiat. Eff. Defects Solids 2008, 163, 293-298. [CrossRef]

84. Velazquez, D.; Seibert, R.; Man, H.; Spentouris, L.; Terry, J. Pulsed laser deposition of single layer, hexagonal boron nitride (white graphene, h-BN) on fiber-oriented $\mathrm{Ag}$ (111)/SrTiO 3 (001). J. Appl. Phys. 2016, 119, 095306. [CrossRef]

85. Glavin, N.R.; Jespersen, M.L.; Check, M.H.; Hu, J.; Hilton, A.M.; Fisher, T.S.; Voevodin, A.A. Synthesis of few-layer, large area hexagonal-boron nitride by pulsed laser deposition. Thin Solid Films 2014, 572, 245-250. [CrossRef]

86. Zagho, M.; Dawoud, H.D.; Bensalah, N.; Altahtamouni, T.M. A brief overview of RF sputtering deposition of boron carbon nitride (CBN) thin films. Emergent Mater. 2019, 2, 79-93. [CrossRef]

87. Lopes, J.M.J.; Vignaud, D. Molecular Beam Epitaxy; Henini, M., Ed.; Elsevier: Amsterdam, The Netherlands, 2018; Chapter 21; pp. 487-513.

88. Tsai, C.L.; Kobayashi, Y.; Akasaka, T.; Kasu, M. Molecular beam epitaxial growth of hexagonal boron nitride on Ni (111). J. Cryst. Growth 2009, 311, 3054-3057. [CrossRef]

89. Nakhaie, S.; Wofford, J.M.; Schumann, T.; Jahn, U.; Ramsteiner, M.; Hanke, M.; Lopes, J.M.; Riechert, H. Synthesis of atomically thin hexagonal boron nitride films on nickel foils by molecula beam epitaxy. Appl. Phys. Lett. 2015, 106, 213108. [CrossRef]

90. Tonkikh, A.A.; Voloshina, E.N.; Werner, P.; Blumtritt, H.; Senkovskiy, B.; Guntherodt, G.; Parkin, S.S.P.; Dedkov, Y.S. Structural and electronic properties of epitaxial multilayer h-BN on $\mathrm{Ni}$ (111) for spintronics applications. Sci. Rep. 2016, 6, 23547. [CrossRef]

91. Merlo, A.; Mokkapati, V.R.S.S.; Pandit, S.; Mijakovic, I. Boron nitride nanomaterials: Biocampatibility and bio-applications. Biomater. Sci. 2018, 6, 2298-2311. [CrossRef]

92. Lin, L.; Xu, Y.; Zhang, S.; Ross, I.M.; Ong, A.C.; Allwood, D.N. Fabrication and Luminescence of Monolayered Boron Nitride Quantum dots. Small 2014, 10, 60-65. [CrossRef]

93. Stengl, V.; Henych, J.; Kormunda, M. Self-Assembled BN and BCN Quantum dots obtained from high intensity ultrasound exfoliated nanosheets. Sci. Adv. Mater. 2014, 6, 1106-1116. [CrossRef]

94. Li, H.; Tay, R.Y.; Tsang, S.H.; Zhen, X.; Teo, E.H.T. Controllable Synthesis of highly luminescent boron nitride quantum dots. Small 2015, 11, 6491-6499. [CrossRef] [PubMed]

95. Jung, J.H.; Kotal, M.; Jang, M.H.; Lee, J.; Cho, Y.H.; Kim, W.J.; Oh, I.K. Defect engineering route to boron nitride quantum dots and edge-hydroxylated functionalization for bio-imaging. RSC Adv. 2016, 6, 73939-73946. [CrossRef]

96. Kumar, R.; Singh, R.K.; Yadav, S.K.; Savu, R. Mechanical pressure induced chemical cutting of boron nitride sheets into boron nitride quantum dots and optical properties. J. All. Comp. 2016, 683, 38-45. [CrossRef] 
97. Liu, M.; Xu, Y.; Wand, Y.; Chen, X.; Ji, X.; Niu, F.; Song, Z.; Liu, J. Boron nitride quantum dots with solvent-regulated blue/green photoluminescence and electrochemiluminescent behavior for versatile applications. Adv. Opt. Mater. 2017, 5, 1600661. [CrossRef]

98. Huo, B.; Liu, B.; Chen, T.; Cui, L.; Xu, G.; Liu, M.; Liu, J. One-step synthesis of fluorescent boron nitride quantum dots via hydrothermal strategy using melamine as nitrogen source for the detection of ferric ions. Langmuir 2017, 40, 10673-10678. [CrossRef]

99. Fan, L.; Zhou, Y.; He, M.; Tong, Y.; Zhong, X.; Fang, J.; Bu, X. Facile approach to controllable boron nitride quantum dots. J. Mater. Sci. 2017, 52, 13522-13532. [CrossRef]

100. Dehghani, A.; Ardekani, S.M.; Lesani, P.; Hassan, M.; Gomes, V.G. Two-photon active boron nitride quantum dots for multiplexed imaging, intercellular ferric ion biosensing, and $\mathrm{pH}$ Tracking in living cells. ACS Appl. Bio Mater. 2018, 1, 975-984. [CrossRef]

101. Ren, J.; Malfatti, L.; Enzo, S.; Carbonaro, C.M.; Calvillo, L.; Granozzi, G.; Innocenzi, P. Boron oxynitride two-colour fluorescent dots and their incorporation in a hybrid organic-inorganic film. J. Colloid Interface Sci. 2019. [CrossRef]

102. Watanabe, K.; Taniguchi, T.; Kanda, H. Direct-bandgap properties and evidence for ultraviolet lasing of hexagonal boron nitride single crystal. Nat. Mater. 2003, 3, 404. [CrossRef]

103. Lei, W.; Portehault, L.; Dimova, R.; Antonietti, M. Boron Carbon Nitride Nanostructures from Salt Melts: Tunable Water-Soluble Phosphors. J. Am. Chem. Soc. 2011, 133, 7121-7127. [CrossRef]

104. Rong, M.; Yang, X.; Huang, L.; Chi, S.; Zhou, Y.; Shen, Y.; Chen, B.; Deng, X.; Liu, Z.Q. Hydrogen Peroxide-Assisted Ultrasonic Synthesis of BCNO QDs for Anthrax Biomarker Detection. ACS Appl. Mater. Interfaces 2019, 11, 2336-2343. [CrossRef]

105. Mura, S.; Ludmerczki, R.; Carbonaro, C.M.; Ricci, P.C.; Casula, F.; Malfatti, L.; Innocenzi, P. Integrating sol-gel and carbon dots chemistry for the fabrication of fluorescent hybrid organic-inorganic films. Sci. Rep. 2019. submitted.

106. Liu, X.; Ye, S.; Qiao, Y.; Dong, G.; Zhang, Q. Facile synthetic strategy for efficient and multi-color fluorescent BCNO nanocrystals. Chem. Commun. 2009, 4073-4075. [CrossRef]

107. Iwasaki, H.; Ogi, T.; Iskandar, F.; Aishima, K.; Okuyama, K. Microwave synthesis of homogeneous and highly luminescent BCNO nanoparticles for the light emitting polymer materials. J. Lumin. 2015, 166, 148-155. [CrossRef]

108. Kang, Y.; Yuan, B.; Zhang, D.; Ma, T.; Huang, X.; Chu, Z.; Lai, K. Green synthetic strategy of BCNO nanostructure and phosphor-based light emitting diodes. J. Lumin. 2016, 179, 501-510. [CrossRef]

109. Xue, Q.; Zhang, H.; Zhu, M.; Wang, Z.; Pei, Z.; Huang, Y.; Huang, Y.; Song, X.; Zeng, H.; Zhi, C. Hydrothermal synthesis of blue-fluorescent monolayer $\mathrm{BN}$ and $\mathrm{BCNO}$ quantum dots for bio bioimaging probes. RSC Adv. 2016, 6, 79090-79094. [CrossRef]

110. Ogi, T.; Kaihatsu, Y.; Iskandar, F.; Wang, W.N.; Okuyama, K. Facile Synthesis of New Full-Color-Emitting BCNO Phosphors with High Quantum Efficiency. Adv. Mater. 2008, 20, 3235-3238. [CrossRef]

(C) 2019 by the authors. Licensee MDPI, Basel, Switzerland. This article is an open access article distributed under the terms and conditions of the Creative Commons Attribution (CC BY) license (http://creativecommons.org/licenses/by/4.0/). 